\title{
Nitrogen in the Earth: abundance and transport
}

\author{
Bjorn Mysen (D)
}

\begin{abstract}
The terrestrial nitrogen budget, distribution, and evolution are governed by biological and geological recycling. The biological cycle provides the nitrogen input for the geological cycle, which, in turn, feeds some of the nitrogen into the Earth's interior. A portion of the nitrogen also is released back to the oceans and the atmosphere via $\mathrm{N}_{2}$ degassing. Nitrogen in silicate minerals (clay minerals, mica, feldspar, garnet, wadsleyite, and bridgmanite) exists predominantly as $\mathrm{NH}_{4}{ }^{+}$. Nitrogen also is found in graphite and diamond where it occurs in elemental form. Nitrides are stable under extremely reducing conditions such as those that existed during early planetary formation processes and may still persist in the lower mantle. From experimentally determined nitrogen solubility in such materials, the silicate Earth is nitrogen undersaturated. The situation for the core is more uncertain, but reasonable Fe metal/silicate nitrogen partition coefficients $(>10)$ would yield nitrogen contents sufficient to account for the apparent nitrogen deficiency in the silicate Earth compared with other volatiles. Transport of nitrogen takes place in silicate melt (magma), water-rich fluids, and as a minor component in silicate minerals. In melts, the N solubility is greater for reduced nitrogen, whereas the opposite appears to be the case for $\mathrm{N}$ solubility in fluids. Reduced nitrogen species $\left(\mathrm{NH}_{3}, \mathrm{NH}_{2}{ }^{-}\right.$, and $\left.\mathrm{NH}_{2}{ }^{+}\right)$dominate in most environments of the modern Earth's interior except the upper $\sim 100 \mathrm{~km}$ of subduction zones where $\mathrm{N}_{2}$ is the most important species. Nitrogen in magmatic liquids in the early Earth probably was dominated by $\mathrm{NH}_{3}$ and $\mathrm{NH}_{2}{ }^{-}$, whereas in the modern Earth, the less reduced, $\mathrm{NH}_{2}{ }^{+}$ functional group is more common. $\mathrm{N}_{2}$ is common in magmatic liquids in subduction zones. Given the much lower solubility of $\mathrm{N}_{2}$ in magmatic liquids compared with other nitrogen species, nitrogen dissolved as $\mathrm{N}_{2}$ in subduction zone magmas is expected to be recycled and returned to the oceans and the atmosphere, whereas nitrogen in reduced form(s) likely would be transported to greater depths. This solubility difference, controlled primarily by variations in redox conditions, may be a factor resulting in increased nitrogen in the Earth's mantle and decreasing abundance in its oceans and atmosphere during the Earth's evolution. Such an abundance evolution has resulted in the decoupling of nitrogen distribution in the solid Earth and the hydrosphere and atmosphere.
\end{abstract}

Keywords: Nitrogen, Recycling, Redox, Speciation, Solubility

\section{Introduction}

Nitrogen has been used as a tracer with which to connect surface reservoirs (atmosphere and the oceans) to the solid Earth. Adequate characterization of the nitrogen exchange within and between reservoirs relies, however, on knowledge of bulk nitrogen contents, nitrogen distribution among various reservoirs, and on nitrogen transport mechanisms within and between the reservoirs as a function of temperature, pressure, redox conditions, and composition of condensed and volatile components.

Correspondence: bmysen@carnegiescience.edu

Geophysical Laboratory, Carnegie Institution of Washington, Washington, D.C., USA

Springer Open

(c) The Author(s). 2019 Open Access This article is distributed under the terms of the Creative Commons Attribution 4.0 International License (http://creativecommons.org/licenses/by/4.0/), which permits unrestricted use, distribution, and reproduction in any medium, provided you give appropriate credit to the original author(s) and the source, provide a link to the Creative Commons license, and indicate if changes were made. 
prior to formation of the Earth. Another possibility is that the Earth was formed with contributions from different embryos with different elemental and isotopic compositions some of which might also be parents of chondritic components (Dauphas 2017). Here, the embryos include major contributions from both carbonaceous and enstatite chondrite as well as other components including ordinary chondrite and a late veneer. The contributions occurred at different stages during Earth formation. Again, however, the nitrogen contents of the individual contributors are uncertain factors.

Nitrogen distribution among reservoirs reflects recycling mechanisms. A major contribution to nitrogen recycling is subduction zones (Goldblatt et al. 2009; Palya et al. 2011) where sediments comprising $\mathrm{N}$-rich organic materials descend into the mantle. Redox conditions play a critical role in the descent process as oxygen fugacity governs the speciation of the nitrogen (Mysen and Fogel 2010). Redox conditions affect the initial recycling step, which is the breakdown of sedimentary organic materials. Redox conditions also govern subsequent nitrogen solubility in minerals, melts, and fluids because the solubility varies with nitrogen speciation. Some of the nitrogen in subducting materials is returned to the surface through devolatilization and nitrogen release. This occurs whenever conditions favor oxidized nitrogen $\left(\mathrm{N}_{2}\right)$, which is not very soluble in magmatic liquids. However, nitrogen is not always oxidized. Under mildly reducing conditions, similar to those defined by the magnetite-wüstite (MW) to quartz-fayalite-magnetite (QFM) oxygen buffers, nitrogen can exist as various $\mathrm{N}-\mathrm{H}$ complexes (Mysen et al. 2008), which can be significantly soluble in subduction zone silicate minerals (Honma and Itahara 1981; Watenphul et al. 2010) and silicate melt (magmatic liquids) (Mysen et al. 2008). Under such circumstances, nitrogen could be transported into the deep mantle. Therefore, there could be greater nitrogen input than output in the Earth, which accords with current observations (Sano et al. 2001; Mitchell et al. 2010; Busigny et al. 2011). Even when nitrogen output near mid-ocean ridges is taken into account, a large difference between nitrogen influx and outflux remains (Busigny et al. 2011). It follows that the nitrogen content of the Earth's interior increased during Earth history while the nitrogen abundance of the oceans and atmosphere may have decreased. It also follows that with the redox-dependent nitrogen solubility in condensed and volatile components, nitrogen abundance (and isotopic compositions?) in the atmosphere, oceans, and crust is decoupled from nitrogen in the deep interior (mantle and core).

The factors that govern the nitrogen abundance and distribution in the Earth's interior in time and space will be discussed in this review. To this end, observations of nitrogen abundance will be examined together with results from laboratory experiments relevant to nitrogen solubility and solution mechanisms in condensed (crystalline and molten materials) and volatile $(\mathrm{C}-\mathrm{O}-\mathrm{H}-\mathrm{N})$ fluids will be discussed. There will be particular emphasis on the consequences of redox-controlled nitrogen speciation as this may help understand the decoupling of terrestrial core and mantle versus crustal nitrogen reservoirs.

\section{Review}

The condensed Earth includes its crust, mantle, and core. Additional reservoirs are the oceans and the atmosphere. To address how nitrogen is distributed, current knowledge of nitrogen recycling and speciation within reservoirs will be summarized briefly first. This will be followed by a discussion of experimental data on nitrogen solubility and solution mechanisms necessary to characterize nitrogen transport behavior in molten silicate (magma).

\section{Nitrogen cycle}

The geological nitrogen cycle describes how nitrogen may be transported through the Earth's interior either as a minor component in minerals or in solution in magmatic liquids and fluids. How nitrogen may be recycled and distributed is illustrated in Fig. 1 (simplified after Bebout et al. 2013). This scheme includes a biological and geological cycle. In the biological cycle, nitrogen is extracted from the atmosphere and used by nitrogen-fixing bacteria. Nitrogen controls both the amount and nature of biomass in aqueous and terrestrial environments (Fogel and Steele 2013). Nitrogen waste from these bacteria is released as $\mathrm{NH}_{4}{ }^{+}$, some of which is oxidized to nitrate and subsequently may be transformed to $\mathrm{N}_{2}$ and returned to the oceans and the atmosphere. Some nitrogen also remains as $\mathrm{NH}_{4}{ }^{+}$initially dissolved in clay minerals and carbonates (Nieder and Benbi 2008, Chapter 1). This nitrogen joins the geological cycle. This cycle begins with sedimentation and diagenesis and ends with release of fluids and/or melting to yield felsic melts in the deep crust and perhaps uppermost mantle (see also Hall 1999, for discussion of nitrogen contents in granite as an indicator of their source material). The nitrogen dissolved in minerals in its reduced form, $\mathrm{NH}_{4}{ }^{+}$, can descend into the deeper mantle. The remainder is released as $\mathrm{N}_{2}$ gas, which is returned to the oceans and the atmosphere (Busigny and Bebout 2013; Li and Keppler 2014; Mallik et al. 2018). This release typically is associated with dehydration and melting of hydrous mineral assemblages in subduction zones, which occurs mostly at depths of about $100 \mathrm{~km}$ and shallower.

An interesting feature of calculated nitrogen transfer into and out of the Earth is that the input mass exceeds the output mass perhaps by a factor of as much as 2 or 3 (Table 1). Some nitrogen may return to the surface at or near ocean ridges, but the nitrogen output in those 


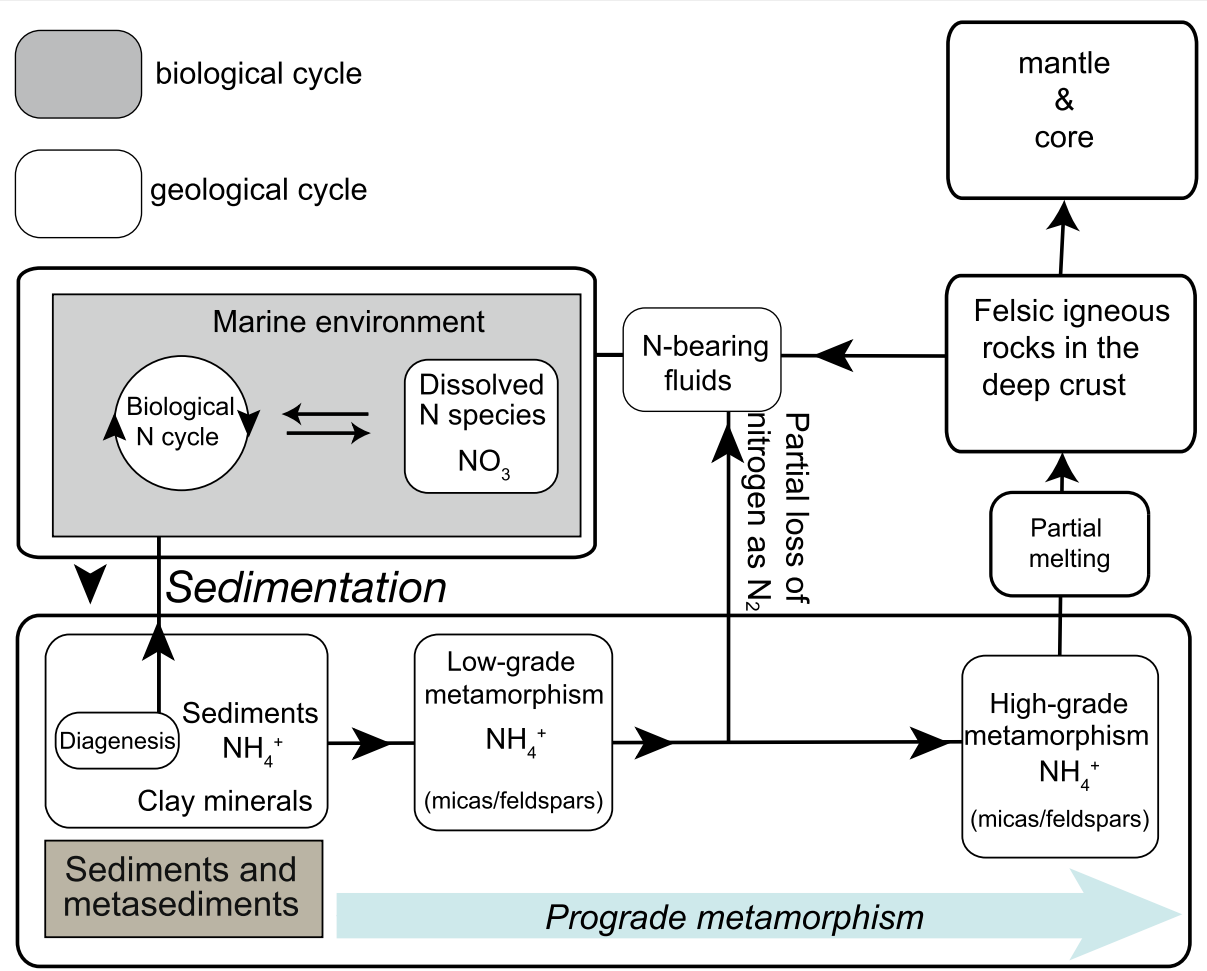

Fig. 1 Simplified schematic representation of integrated geologic and biologic recycling schemes of nitrogen in the Earth's crust (modified from Bebout et al. 2013)

environments is insufficient to account for the difference. There are some variations in these numbers, but the general conclusion of a net nitrogen gain of the Earth's interior over time appears real (Sano et al. 2001; Mitchell et al. 2010; Halama et al. 2014). This phenomenon may be related to the observation that mineral/melt (or fluid) $\mathrm{NH}_{4}^{-}$partition coefficients are not greatly different from unity (Busigny and Bebout 2013). Therefore, even during melting or fluid release in the Earth's mantle, some of the nitrogen brought to the deep mantle may not return to the Earth's surface (see also Palya et al. 2011 and Busigny and Bebout 2013, for additional discussion of this).

Table 1 Terrestrial nitrogen reservoirs (modified after Goldblatt et al. 2009; Palya et al. 2011)

\begin{tabular}{ll}
\hline Reservoir & $\%$ in reservoir \\
\hline Atmosphere & 27.0 \\
Continental crust & 14.2 \\
Oceanic crust & 2.2 \\
Mantle & 56.7 \\
Oceans & 0.005 \\
Biomass (incl. soil, vegetation, & 0.000062 \\
and marine biota) & \\
\hline
\end{tabular}

\section{Nitrogen reservoirs}

In terms of total mass, the main reservoir is the mantle (Table 1). However, the summary in Table 1 does not include the Earth's core for which nitrogen estimates vary significantly (Dalou et al. 2017; Roskosz et al. 2013). Major uncertainties affecting assessment of the nitrogen abundance in the core are silicate/melt partition coefficients, the extent of pressure-dependent nitrogen partitioning between metal and silicate, and redox conditions during core separation. These variables are somewhat interdependent and are central factors governing nitrogen cycles in the Earth.

The agents for materials transfer within and between are silicate melts (magma) and sometimes $\mathrm{COHN}$ volatiles. Nitrogen and other volatiles would have been dissolved in the high-pressure silicate magma ocean of the early Earth in which the solubility of the volatile species likely greatly exceeded their abundance. This is because the solubility of volatiles in silicate melts, including nitrogen species, in the $\mathrm{C}-\mathrm{O}-\mathrm{H}-\mathrm{N}$ system is on the order of several thousand ppm even at pressures corresponding to depths of a few kilometers. The solubility increases with increasing pressure (see Mysen and Richet 2019; Chapters 14-18, for detailed review of this information). A few thousand ppm is orders of magnitude greater than the content of these volatiles in the silicate 
Earth (Marty 2012; Halliday 2013; Armstrong et al. 2015).

\section{Nitrogen in the crust}

The oceanic sedimentary crust is dominated by shale, sandstone, and carbonate. Most of the nitrogen is found in sandstone $(260 \pm 10 \mathrm{ppm})$ and shale and silt with $860 \pm$ $64 \mathrm{ppm}$ nitrogen (Fig. 2; see also Johnson and Goldblatt 2015). In biogenic continental sediments, the nitrogen content averages at $1930 \pm 1540 \mathrm{ppm}$. Sediments deposited in continental environments differ somewhat from oceanic materials both in their nature and nitrogen content. Clastic sediments from continental environments can be quite nitrogen-rich with an average abundance of $670 \pm 56$ ppm (Fig. 3).

Much of the nitrogen in crustal igneous rocks may be returned to the Earth's interior in subduction zones. The nitrogen concentration in the igneous rocks varies widely. For example, granite formed by partial melting of biomass precursors typically is ammonium-rich with up to more than $100 \mathrm{ppm} \mathrm{N}$ held in mica and feldspar minerals, whereas granite formed by fractional crystallization or melting of mafic rocks is nitrogen poor with only several ppm N (Hall 1999). Other igneous rocks such as gabbro and tonalite contain on average $10 \mathrm{ppm}$ or less $\mathrm{N}$ (Johnson and Goldblatt 2015).

The main influx of nitrogen to the Earth's interior is from sediments in subduction zones (Busigny et al. 2011). Some nitrogen from the descending sediment column is released as $\mathrm{N}_{2}$ and returned to the oceans and the atmosphere. The proportion of nitrogen remaining in sedimentary and metamorphic rocks decreases with increasing depth (e.g., Plessen et al. 2010).

The extent to which release of $\mathrm{N}_{2}$ occurs instead of transport as $\mathrm{NH}_{4}{ }^{+}$to greater depth in subduction zones depends on the thermal gradient and oxygen fugacity. Steep thermal gradients lead to $\mathrm{N}_{2}$ formation. Cold subduction zones lead to greater nitrogen loss (Bebout et al. 1999; Halama et al. 2014). Under oxidizing conditions such as those near the QFM-NNO range, which is typical for subduction zone magmatism (Carmichael and Ghiorso 1990), most of the nitrogen is released as $\mathrm{N}_{2}$. Under more reducing conditions, the nitrogen remains as $\mathrm{NH}_{4}{ }^{+}$and descends into the deep mantle. Ammonia and derivative functional groups in this latter environment are retained in clay minerals, micas (phlogopite and phengite), and feldspars (Hall 1999; Elkins et al. 2006; Watenphul et al. 2009; Mitchell et al. 2010; Plessen et al. 2010; Palya et al. 2011; Yoshioka et al. 2018).

The metamorphic processes operating during subduction of sediments likely would lead to a gradual decrease with depth of bulk nitrogen content of subduction zone materials (increasing metamorphic grade). This effect has been seen, for example, in older exposed metamorphic terranes (Plessen et al. 2010; Busigny and Bebout 2013). It is particularly evident in the rapid loss of nitrogen from mica minerals, which are the primary carriers of nitrogen (Fig. 4). In addition, as subducting crust descends deeper into the mantle, a number of $\mathrm{N}$-bearing phases can be stable with hollandite (a high-pressure K-feldspar
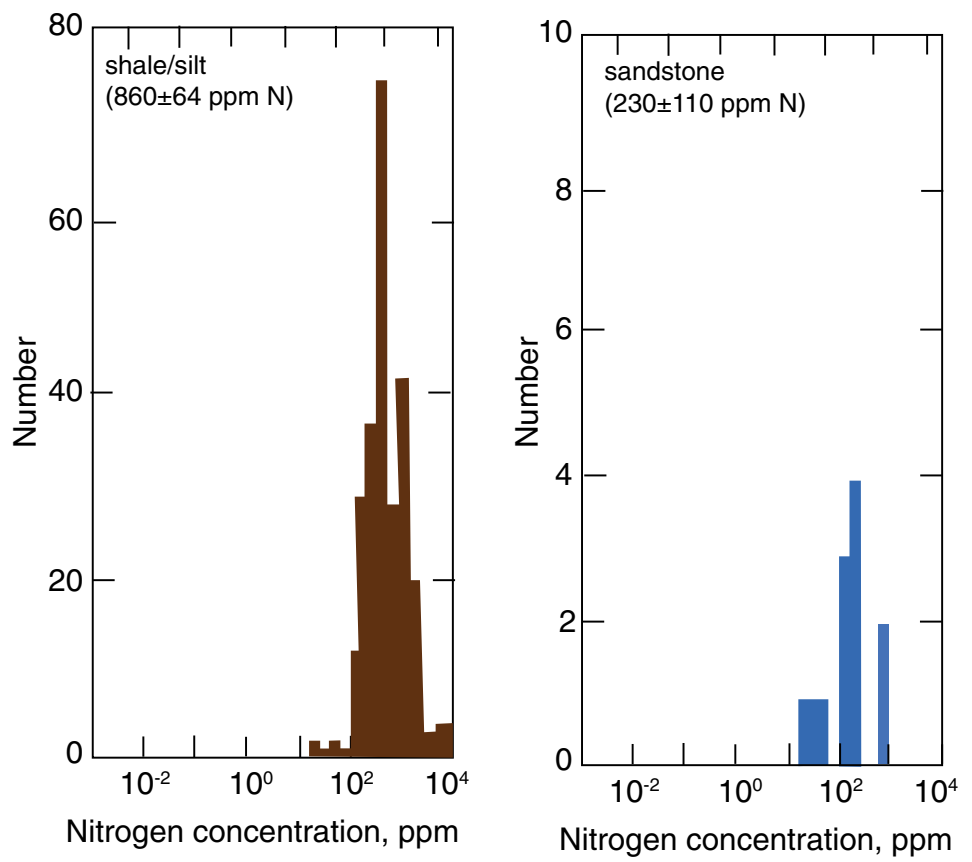

Fig. 2 Distribution of nitrogen concentrations in various oceanic sedimentary rocks modified after Johnson and Goldblatt (2015) 

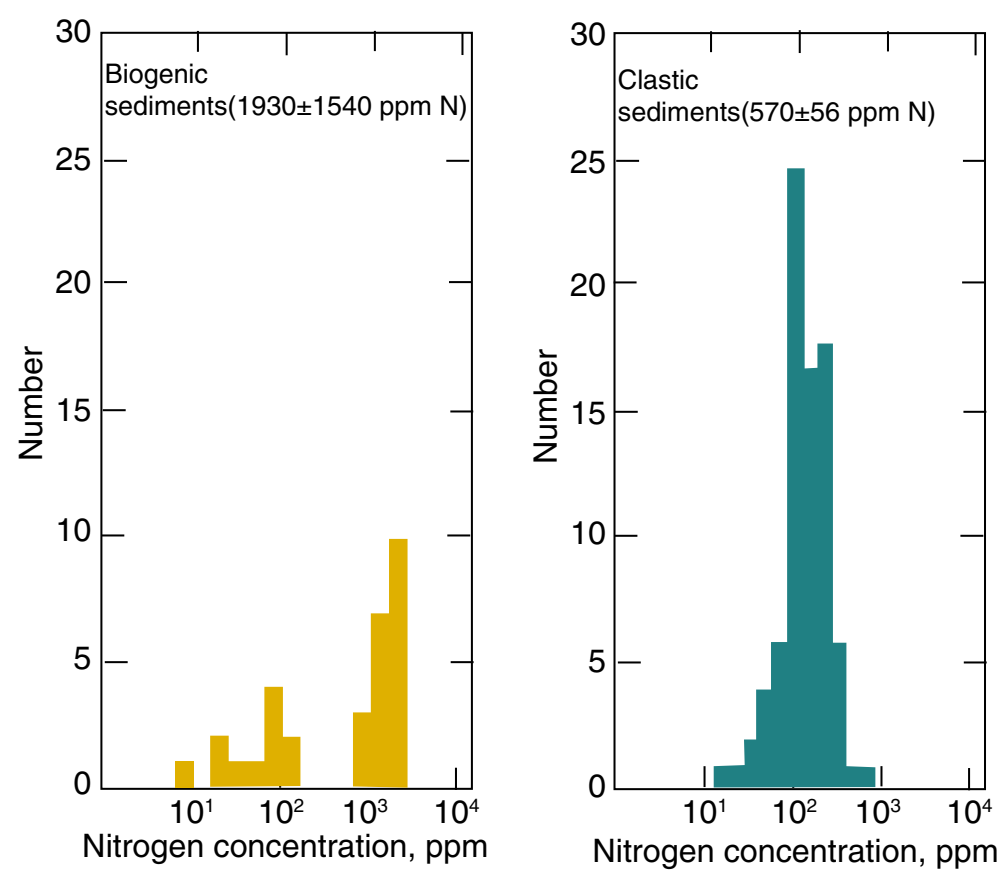

Fig. 3 Distribution of nitrogen concentrations in various continental sedimentary rocks modified after Johnson and Goldblatt (2015)

analogue) as the highest-pressure N-bearing mineral (Watenphul et al. 2009).

\section{Nitrogen in the mantle}

The difference in nitrogen input and output (Table 1) may imply that nitrogen stored in the mantle and perhaps the core of the Earth may have increased through the Earth's history. The nitrogen abundance in the modern mantle commonly is considered near 1 ppm (Fig. 5).

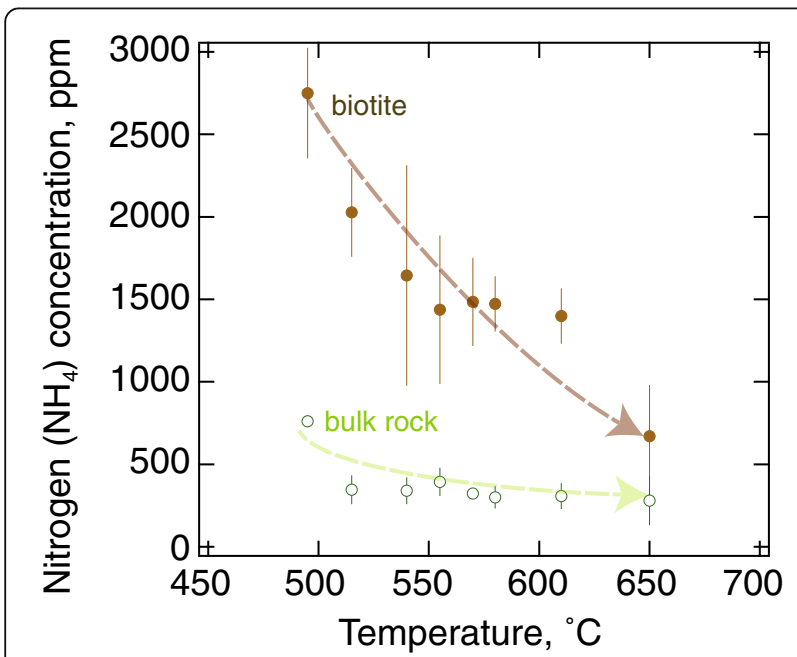

Fig. 4 Nitrogen content of bulk rock and of its biotite in metamorphic rocks from Western Maine (USA) as a function of temperature (metamorphic grade) (data from Plessen et al. 2010)
Nitrogen solubility as high as near $25 \mathrm{ppm}$ in forsterite, pyroxene, and garnet have been reported in an experimental study in the 1.5-3.0 GPa range with the oxygen fugacity controlled at those of the NNO and IW buffer (Li et al. 2013). From least squares fitting to all the data obtained, Li et al. (2013) derived the following expressions for solubility;

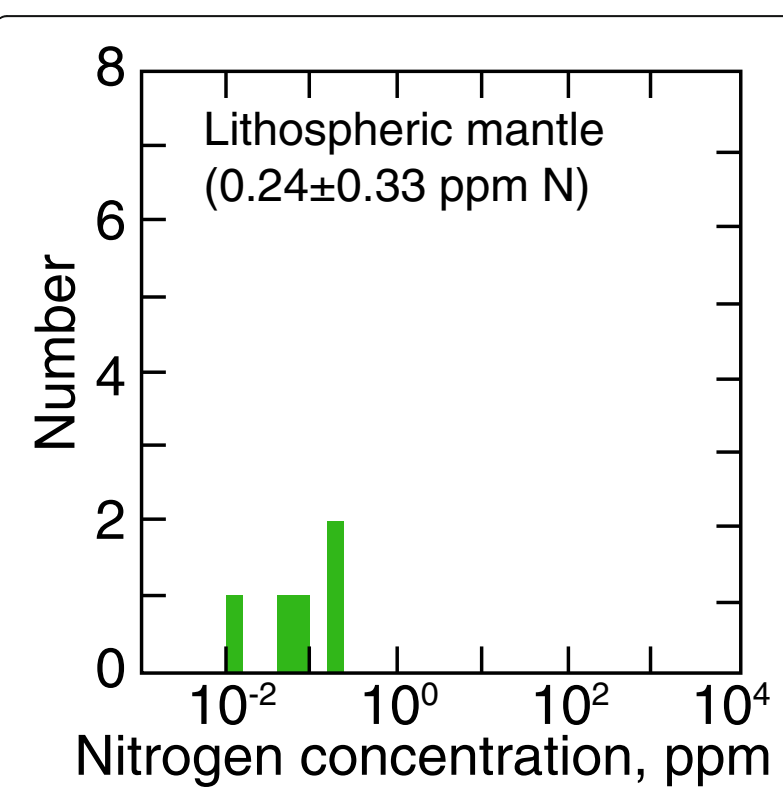

Fig. 5 Distribution of nitrogen concentrations in mantle rocks modified after Johnson and Goldblatt (2015) 
forsterite $: \log C_{\mathrm{N}}=2.15-6.8 \cdot 10^{3} / \mathrm{T}(\mathrm{K})$

$$
+0.0027 \mathrm{P}(\mathrm{GPa})-0.43 \Delta \mathrm{NNO} \text {, }
$$

and

$$
\text { pyroxene and garnet : } \begin{aligned}
\log C_{\mathrm{N}}= & 6.48-8.7 \cdot 10^{3} / \mathrm{T}(\mathrm{K}) \\
& +0.00086 \mathrm{P}(\mathrm{GPa})-0.122 \Delta \mathrm{NNO},
\end{aligned}
$$

where $\triangle \mathrm{NNO}$ is the oxygen fugacity difference from that of the nickel/nickel oxide oxygen buffer $[\Delta \mathrm{NNO}=\log$ $\left.\mathrm{f}_{\mathrm{O} 2}-\log f_{\mathrm{O} 2}(\mathrm{NNO})\right]$. Partition coefficients among upper mantle minerals are summarized in Table 2.

The nitrogen solubility in garnet is the highest among upper mantle silicate minerals (olivine, pyroxenes, and garnet). Olivine dissolves the least nitrogen with about 2-3 ppm at the oxygen fugacity controlled by the Fe-FeO buffer (IW) (Fig. 6). The nitrogen solubility in these upper mantle minerals is, therefore, higher than the suggested upper mantle nitrogen concentration $(\leq 1 \mathrm{ppm}$ $\mathrm{N})$. This means that the upper mantle is undersaturated with respect to nitrogen. Redox conditions are important, however, so that the more reducing the environment, the greater is the nitrogen solubility (Yoshioka et al. 2018). The $\mathrm{NH}_{4}{ }^{+}$solubility can also depend on solid solutions. For example, there is a positive correlation between nitrogen content of enstatite and its $\mathrm{Al}_{2} \mathrm{O}_{3}$ concentration (Fig. 7).

The highest nitrogen content in upper mantle minerals is found in diamonds (Smith and Kopylova 2014) with an average $\mathrm{N}$ concentration of $235 \mathrm{ppm}$ in diamonds from the lithosphere ( $\leq 200 \mathrm{~km}$ crystallization depth). This region also yields the smallest proportion of the

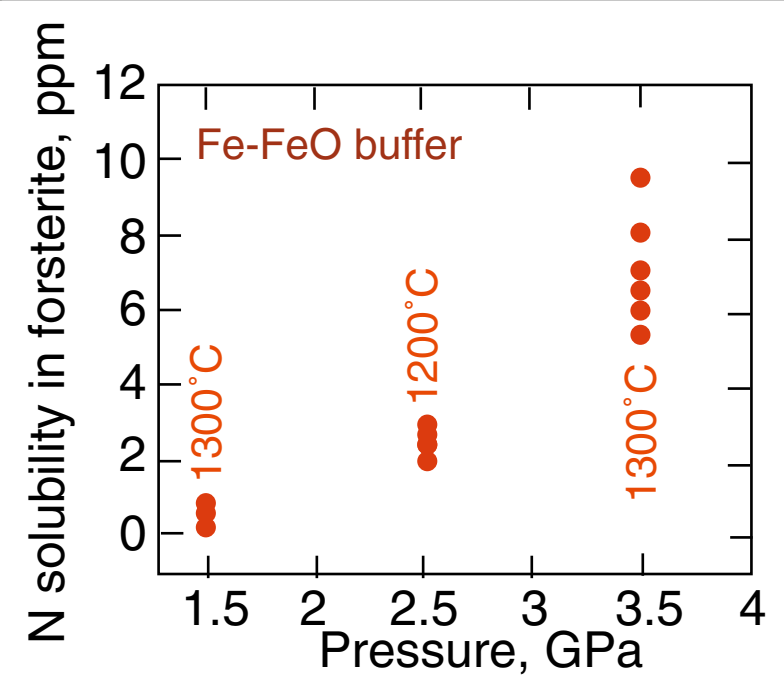

Fig. 6 Summary of nitrogen solubility of forsterite at different oxygen fugacities indicated and fixed temperature and pressure (modified from Li et al. 2013)

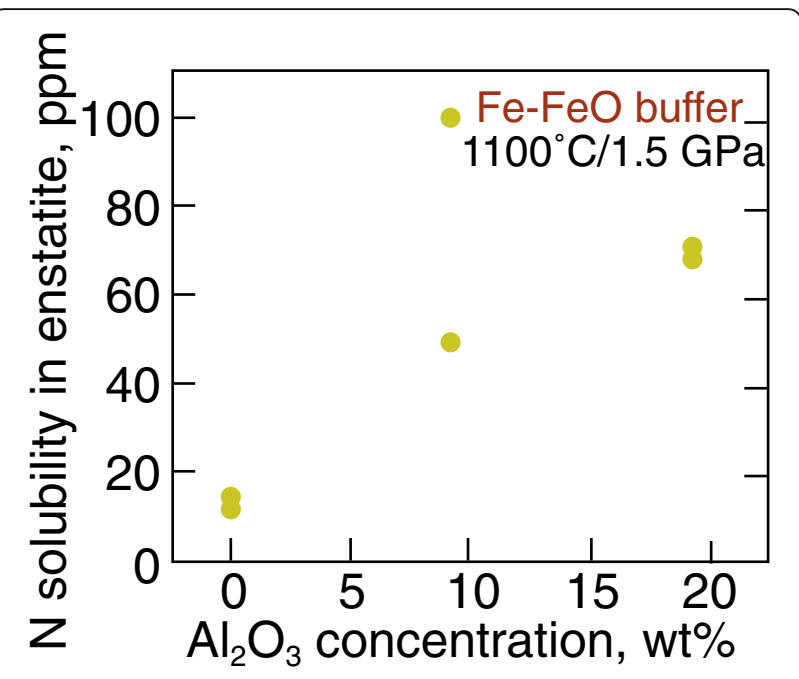

Fig. 7 Nitrogen solubility in enstatite as a function of its $\mathrm{Al}_{2} \mathrm{O}_{3}$ content at fixed temperature, pressure, and oxygen fugacity as indicated on the figure (modified from Li et al. 2013)

nitrogen-poor type II (low nitrogen) diamonds. At greater depth, down to the transition zone near $410 \mathrm{~km}$, the nitrogen concentration is less. The average nitrogen content of diamonds from the lower mantle is $17 \mathrm{ppm}$ and the proportion of N-poor Type II diamonds is increased. It has been suggested that the differences between these latter diamonds and the upper mantle diamonds formed in the lithosphere reflect different redox conditions during diamond growth. The mantle appears to become increasingly reducing with depth (McCammon 2005). However, under such reducing conditions, nitrogen incorporation in diamond is lower than when oxidizing because there may be competition between solution of nitrogen in diamond and metallic Fe to form iron nitrides (Miyazaki et al. 2004; Zhang and Yin 2012). In laboratory experiments at high pressure and temperature, Polyanov et al. (2014) observed an order of magnitude higher nitrogen content in diamonds grown in equilibrium with carbonate melt compared with diamond grown in contact with metallic iron. The highest nitrogen contents recorded are from microdiamonds from the high-pressure metamorphic terrane of the Kokchetav massif in Kazakhstan where nearly 4500 ppm $\mathrm{N}$ in diamonds has been reported (De Corte et al. 1998).

The abundance of nitrogen in the transition zone of the Earth's mantle (410-670 km depth) and below (>670 km depth) is not easily determined, but has been suggested to be around 5 ppm (Marty 2012). The nitrogen solubility in the silicate phases in the pressure range corresponding to this depth is, however, considerably greater than such a value. For example, the nitrogen solubility in wadsleyite [a high-pressure polymorph of (Fe, Mg) ${ }_{2} \mathrm{SiO}_{4}$ ] exceeds $50 \mathrm{ppm}$ at pressures corresponding to the top of 
Table 2 Nitrogen partition coefficients

\begin{tabular}{ll}
\hline & $K_{D}$ \\
\hline Muscovite/biotite & $0.43 \pm 0.11$ \\
K-feldspar/biotite & $0.38 \pm 0.08$ \\
Plagioclase/biotite & $0.11 \pm 0.04$ \\
K-feldspar/muscovite & $0.85 \pm 0.15$ \\
Plagioclase/K-feldspar & $0.32 \pm 0.16$ \\
\hline
\end{tabular}

the transition zone (near $410 \mathrm{~km}-15 \mathrm{GPa}$ ) and increases with increasing pressure (Fig. 8; see also Yoshioka et al. 2018). The nitrogen partition coefficients between wadsleyite and the other major lower mantle silicate phases (ringwoodite and bridgmanite) are between 2 and about 8 (Table 3), which means that all of the lower mantle silicates could accommodate several tens of ppm N. Based on this information, the Earth's lower mantle is undersaturated with respect to nitrogen (Yoshioka et al. 2018).

The discussion in the previous paragraph does not consider inclusions in diamond. Iron nitrides, $\mathrm{Fe}_{3} \mathrm{~N}$ and $\mathrm{Fe}_{2} \mathrm{~N}$, have been reported as inclusions in diamonds from the lower mantle (Kaminsky and Wirth 2017). Among these inclusions, there appear to be complete solid solutions across from carbides to nitrides (Fig. 9). Such observations accord with experimental data, which indicate that $(\mathrm{Fe}, \mathrm{Ni})$ nitrides are stable under lower mantle temperature and pressure conditions (Adler and Williams 2005). Finally, there is also nitrogen in lower mantle diamonds with an average concentration of $17 \mathrm{ppm}$. This nitrogen abundance information lends further support to the conclusion that the lower mantle is undersaturated in nitrogen.

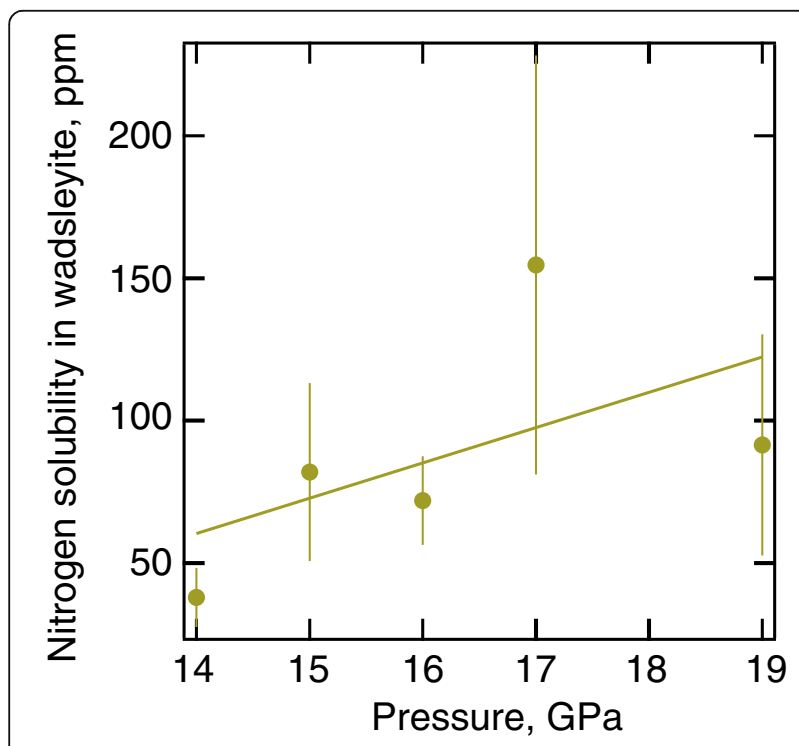

Fig. 8 Nitrogen solubility in wadsleyite $\left[(\mathrm{Fe}, \mathrm{Mg})_{2} \mathrm{SiO}_{4}\right]$ as a function of pressure (modified after Yoshioka et al. 2018)
Table 3 Nitrogen partition coefficients among lower mantle silicate phases (data from Yoshioka et al. 2018)

\begin{tabular}{ll}
\hline & Partition coefficients \\
\hline wadsleyite/olivine & $5.1 \pm 2.1$ \\
wadsleyite/ringwoodite & $2.0 \pm 1.2$ \\
ringwoodite/bridgmanite & $4.2 \pm 0.3$ \\
metal/bridgmanite & $\sim 98$ \\
\hline
\end{tabular}

\section{Nitrogen in the Earth's core}

Nitrogen is one of the light elements proposed for the Earth's core (Halliday 2013; Dalou et al. 2017; Grewal et al. 2019). Nitrogen also is an attractive core component because such a core might contain the so-called missing nitrogen of the silicate Earth (Fig. 10). Iron nitrides are possible candidates for the Earth's core (Adler and Williams 2005; Litasov et al. 2017).

Whether or not nitrogen could be a component of the Earth's core depends on the variables that could govern its nitrogen content. The nitrogen abundance values are strongly dependent on silicate/metal partition coefficients (Roskosz et al. 2013; Dalou et al. 2017), which, in turn, are sensitive to temperature, pressure, redox conditions, core, and silicate composition. For example, Dalou et al. (2017) observed experimentally that metal/ silicate partition coefficients vary by about 1.5 orders of magnitude (Fig. 11) within the 3-4 orders of magnitude oxygen fugacity range suggested to exist during formation of the Earth's core (Li and Agee 1996; Wade and Wood 2005; Rubie et al. 2011). A metal/silicate partition coefficient for nitrogen above 10 appears needed in order to account for the $\mathrm{N}$ deficiency illustrated in Fig. 10 with the

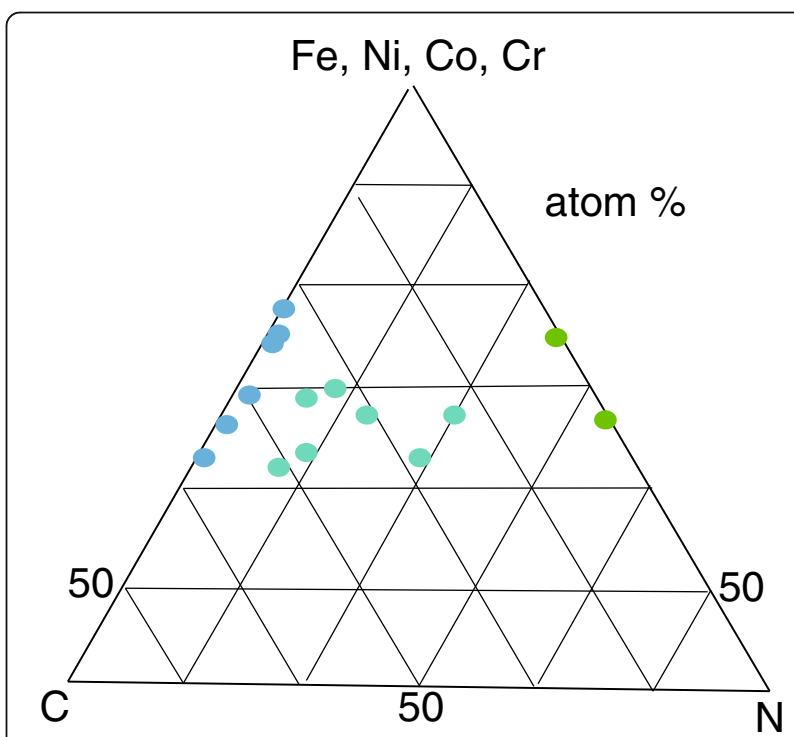

Fig. 9 Mineral phases in the system $\mathrm{C}-\mathrm{N}-(\mathrm{Fe}, \mathrm{Ni}, \mathrm{Co}, \mathrm{Cr})$ found as inclusions in lower mantle diamonds (data from Kaminsky and Wirth 2017) 


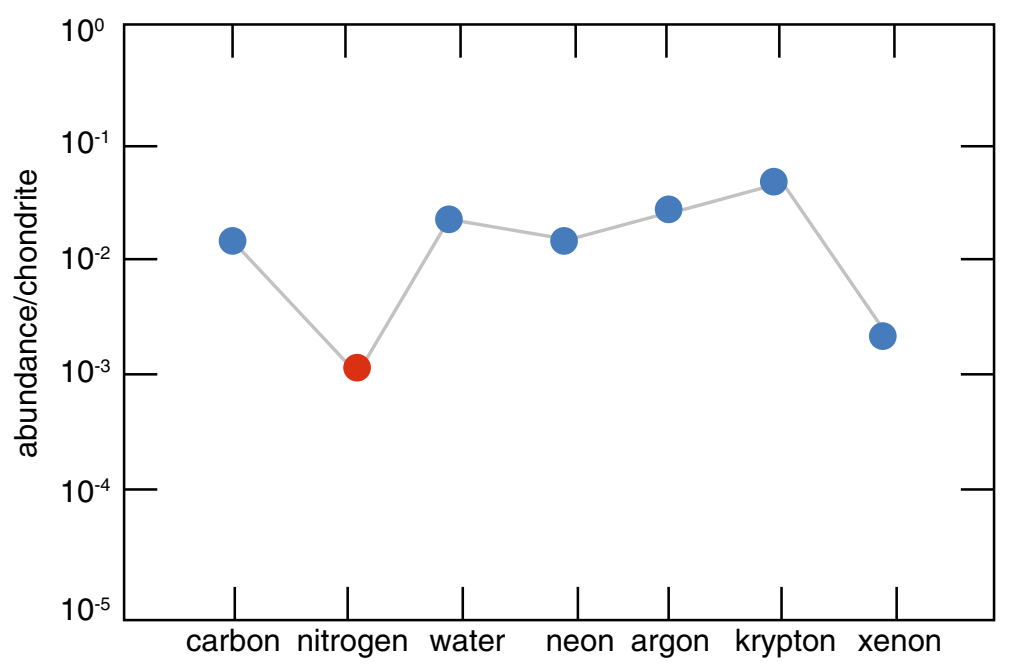

Fig. 10 Chondrite-normalized noble gas, carbon, and nitrogen content of the silicate earth (modified from Marty 2012)

assumption of an early Earth nitrogen content near $30 \mathrm{ppm}$ (Marty 2012). An oxygen fugacity about an order of magnitude more reducing than that of the iron-wüstite oxygen buffer would be necessary for metal/silicate partition coefficients to be in this range. However, Roskosz et al. (2013) observed that the nitrogen content of iron and iron-nickel alloys equilibrated with silicate increases significantly with increasing pressure and also is somewhat sensitive to nickel content (Fig. 12). This feature, in turn, would affect the oxygen fugacity necessary to obtain the appropriate metal/silicate partition coefficients.

Roskosz et al. (2013) estimated the nitrogen content of the core by using the expression;

$$
C_{\mathrm{Si} \text { earth }}=C_{\text {protoearth }} /\left[1+M_{\text {core }} / M_{\mathrm{Si} \text { earth }}\left(K_{\mathrm{D}}{ }^{\text {metal } / \text { silicate }}(\mathrm{N})-1\right)\right] \text {, }
$$

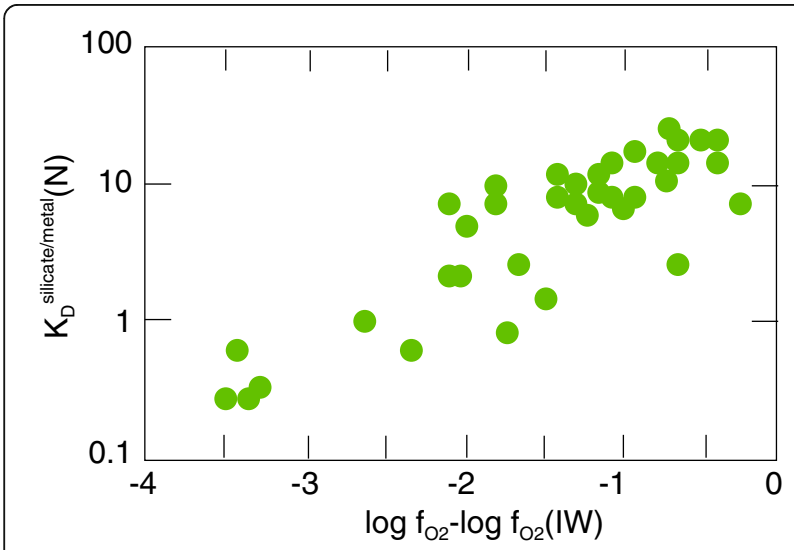

Fig. 11 Fe-rich metal/silicate nitrogen partition coefficient, $K_{D}(N)$, as a function of oxygen fugacity expressed relative to the oxygen fugacity of the iron-wüstite (IW) buffer expressed as base10 log (data from Dalou et al. 2017) where $K_{\mathrm{D}}^{\text {metal/silicate }}(\mathrm{N})$ is the metal/silicate partition coefficient, $C_{\mathrm{Si} \text { earth }}$ and $C_{\text {protoearth }}$ are the nitrogen contents of the silicate earth and proto-Earth, and $M_{\text {core }}$ and $M_{\mathrm{Si}}$ earth are the masses of the core and the silicate Earth. They assumed a proto-Earth comprising 2\%

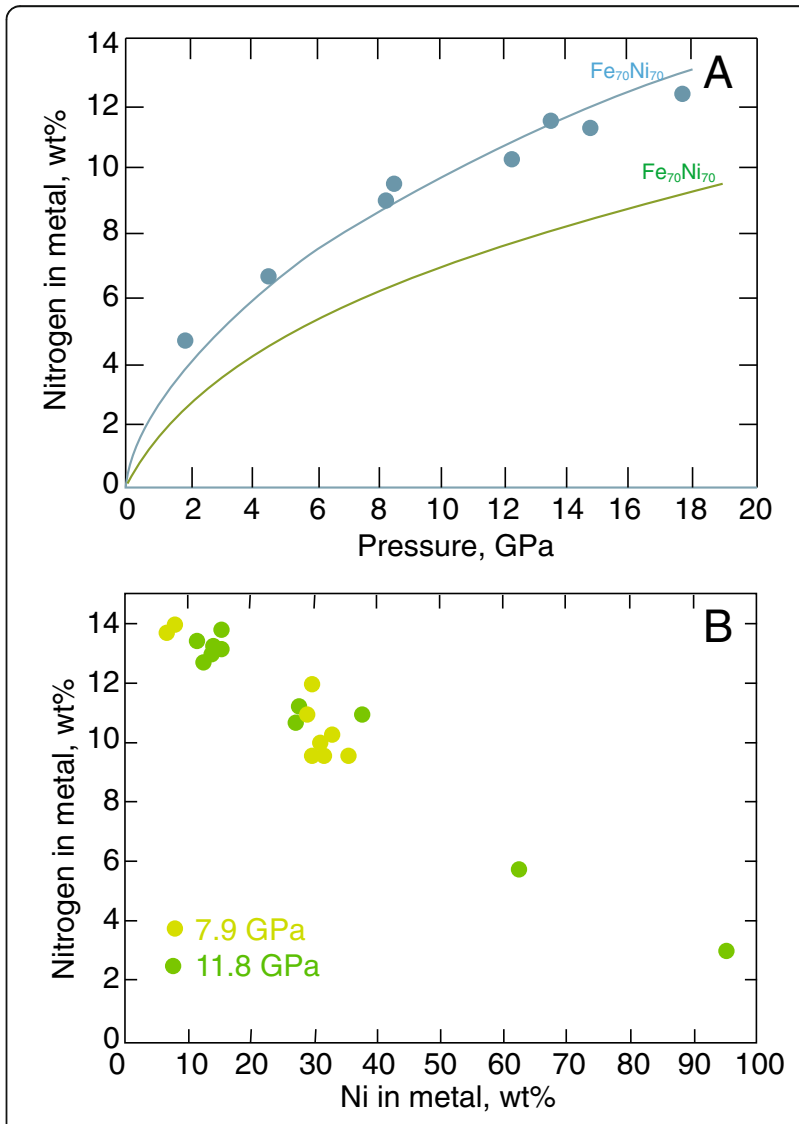

Fig. 12 Nitrogen solubility in Fe-rich (Fe,Ni) metal as a function of pressure (a) and Ni content (b) (data from Roskosz et al. 2013) 
carbonaceous chondrite material with $1500 \mathrm{ppm} \mathrm{N}$. A partition coefficient near 20 would be needed to reach a nitrogen content of the silicate earth near 1-4 ppm and remove the nitrogen deficiency indicated in Fig. 12. However, the nitrogen content of the precursor material or materials is quite uncertain and depends on thermal history of the precursor materials prior to aggregation of the Earth (Cody et al. 2008) as well as proportions of several different precursor materials that may have contributed the proto-Earth over a period of time (Dauphas 2017).

The nitrogen abundance depends on the extent of processing undergone by a presumed starting material prior to accumulation to form the proto-Earth because of the nitrogen loss likely during such processes (Fig. 13; see also Alexander et al. 2007; Bergin et al. 2015). It is not well known, therefore, what $K_{\mathrm{D}}{ }^{\text {metal/silicate }}(\mathrm{N})$ values would be necessary to account for the nitrogen deficiency in the silicate Earth. In the Dauphas (2017) model, four precursor materials (carbonaceous chondrite, enstatite chondrite, ordinary chondrite, and late veneer) contributed to the overall composition. The nitrogen content of the resulting Earth clearly would be strongly dependent on the proportions of the contributing precursor materials.

\section{Nitrogen transport}

Evolution of the terrestrial nitrogen reservoirs following their original composition and volume in the proto-Earth

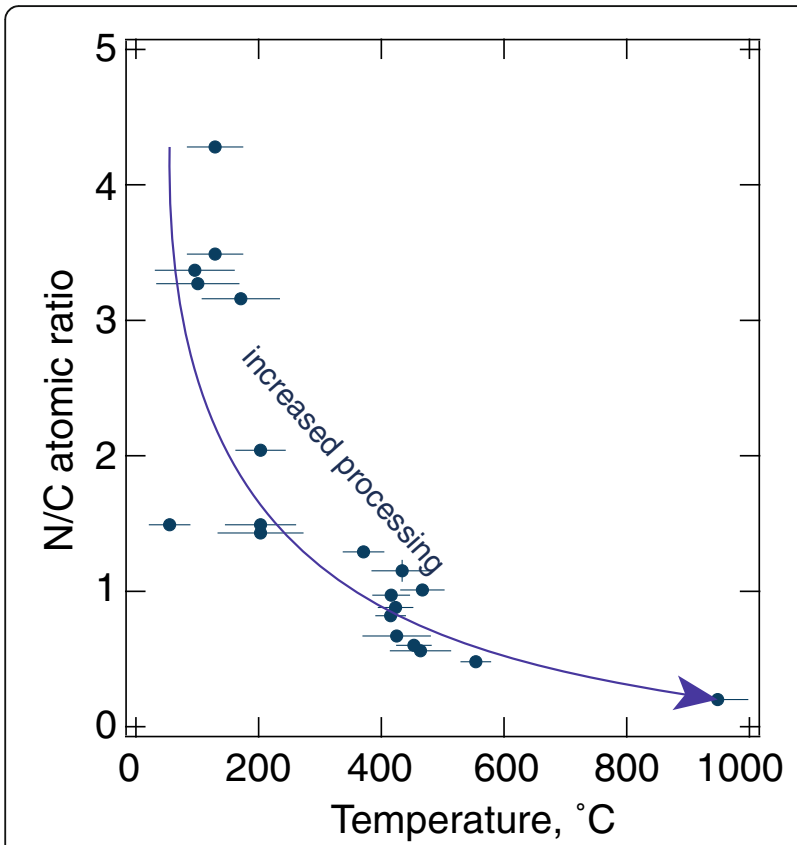

Fig. 13 Relationship between N/C atomic ratios of carbonaceous chondrites and the maximum temperature experienced (temperature of processing) (data from Alexander et al. 2007; Cody et al. 2008) was accomplished by mass transfer with magma (silicate melt) and fluids in the C-O-H-N systems. Characterization of these processes rely on understanding nitrogen solubility, solution mechanisms, and nitrogen partitioning between coexisting minerals, melts, and fluids.

\section{Solubility and solution mechanisms}

The nitrogen solubility and speciation in magmatic melts and aqueous fluids are sensitive functions of redox conditions, temperature, pressure, silicate, and fluid composition. These variables will, therefore, affect the distribution of nitrogen in the Earth. For example, redox conditions are important because $\mathrm{N}_{2}$ is incompatible in silicate minerals, whereas reduced nitrogen is compatible (Bebout et al. 2013). In this latter case, during melting and fluid release in the mantle, some nitrogen will, therefore, remain in crystalline mantle. This feature together with oxygen fugacity variations are key factors controlling temporal changes in mantle (and core?) nitrogen content.

Oxidizing conditions Oxidizing conditions are defined as an $\mathrm{f}_{\mathrm{O} 2}$ near that of the QFM oxygen buffer and above. Nitrogen in fluids and melts exists principally as molecular $\mathrm{N}_{2}$ under oxidizing conditions (Mysen et al. 2014; Li et al. 2015).

The solubility of $\mathrm{N}_{2}$ in aqueous fluids at high temperature and pressure has not been studied extensively. However, fluid/melt partition coefficients for $\mathrm{N}_{2}$ ranges between 1.5 and 3 in the $500-800{ }^{\circ} \mathrm{C}$ temperature range (Fig. 14).

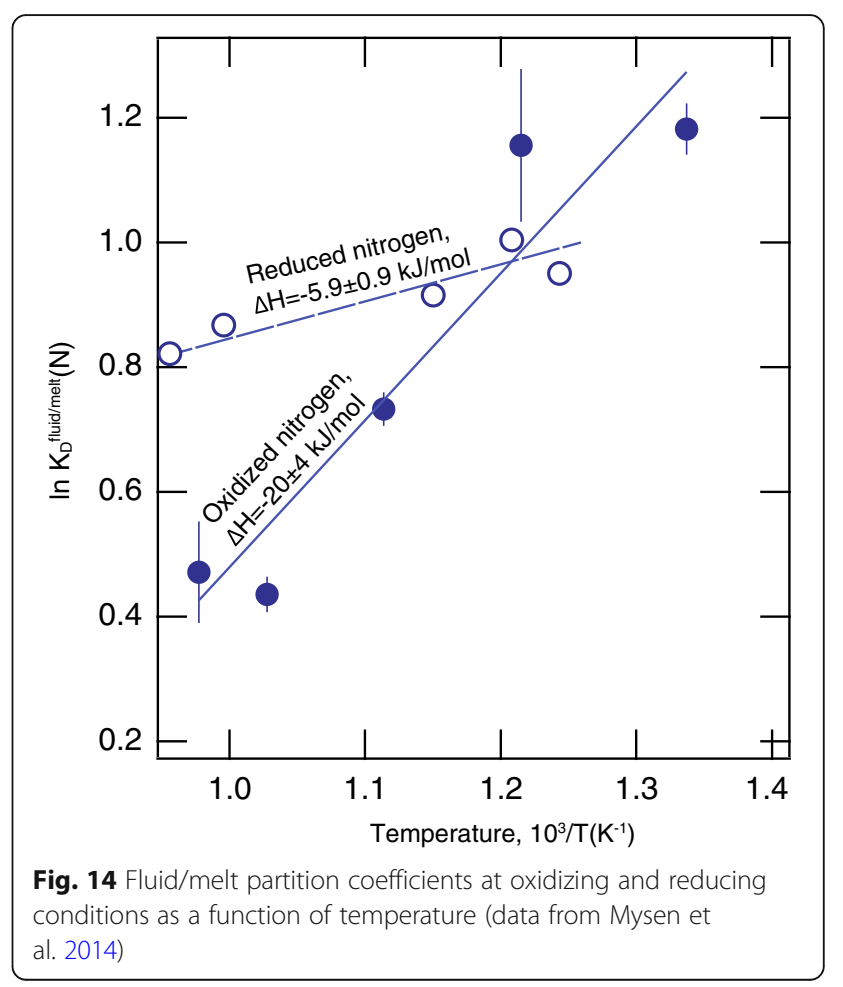


The experimental results in Fig. 14 were recorded over a 0.1-1.5 GPa pressure range. There is a pressure range associated with this temperature range because in the diamond cell experiments used in those experiments, pressure is positively correlated with temperature (see also Bassett et al. 1994; for details of experimental procedures). At lower pressures, the partition coefficient increases and reaches values of several hundred in the 0.1-0.2 GPa range ( $\mathrm{Li}$ et al. 2015). The $\mathrm{N}_{2}$ solubility in fluids is, therefore, considerably greater than in magmatic liquids (silicate melt).

The $\mathrm{N}_{2}$ solubility commonly follows Henry's Law with a Henry's Law constant near $5 \cdot 10^{-9} \mathrm{~mol} \mathrm{~g}^{-1}$ bar $^{-1}$ (Javoy and Pineau 1991; Libourel et al. 2003; Roskosz et al. 2006). Some variations in the Henry's Law constant may be ascribed to compositional dependence of the $\mathrm{N}_{2}$ solubility similar to the behavior of noble gases in silicate melts. These variables include extent of silicate polymerization (which is mostly linked to $\mathrm{Si}+\mathrm{Al}$ contents), aluminum substitution of silicon, and the electronic properties and proportions of network-modifying cations (alkali metals and alkaline earths).

The $\mathrm{N}_{2}$ solubility increases as the concentration of three-dimensional cavities in the silicate structure increases, which is similar to the solubility behavior of noble gases (Carroll and Draper 1994; Zhang et al. 2010). The more polymerized a melt, the greater the concentration of three-dimensional cavities and, therefore, the greater the $\mathrm{N}_{2}$ solubility. The cavity abundance, in turn, is positively correlated with $\mathrm{Si}+\mathrm{Al}$ concentration of melts. Moreover, the cavity size likely varies with the types of alkali and alkaline earth cation or cations in the structure (LeLosq et al. 2015) where larger cations favor larger cavities. Larger cavities would enhance the solubility of gas molecules and atoms (Zhang et al. 2010). The increase in $\mathrm{N}_{2}$ solubility in a silicate melt as the radius of the network-modifier cation increases is also consistent with this model (Roskosz et al. 2006). The $\mathrm{N}_{2}$ solubility in silicate melts falls on the line defining solubility of noble gases as a function of their atomic radius (Carroll and Draper 1994; see also Fig. 15) thus suggesting similar solution behavior of noble gases and molecular $\mathrm{N}_{2}$. The positive correlation between the extent of polymerization of silicate melts and nitrogen and noble gas solubility (Miyazaki et al. 1995; Roskosz et al. 2006) is consistent with this solubility model.

There are, however, conditions under which additional nitrogen solution mechanism(s) may operate even under oxidizing conditions. Roskosz et al. (2006) found that when the silicate melt structure becomes sufficiently depolymerized, perhaps similar to the structure of basalt melt at or near ambient pressure, the nitrogen solubility does not follow Henry's Law (Fig. 16). Furthermore, they observed that those deviations become less prevalent with increasing pressure, and more prevalent the more

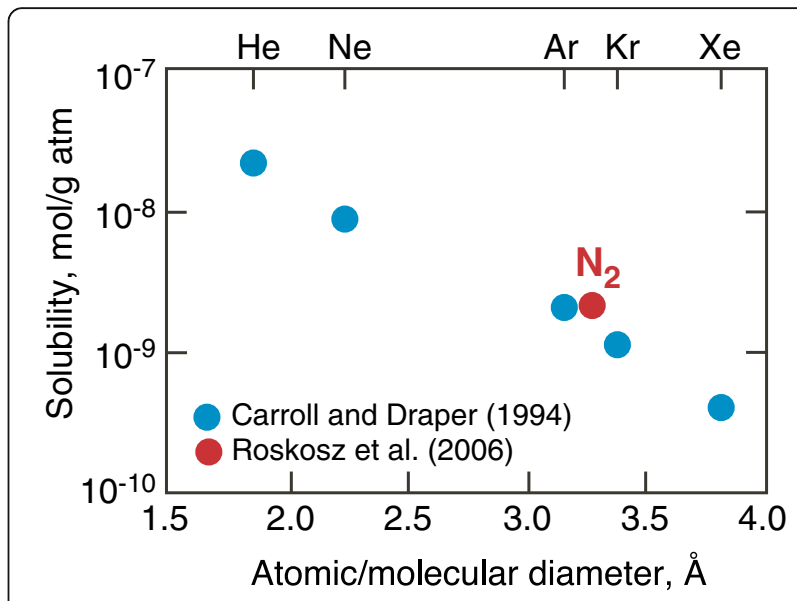

Fig. 15 Nitrogen solubility in basalt melt at ambient pressure shown together with solubility of noble metals as a function of their atomic/molecular radius (data from Carroll and Draper 1994; Roskosz et al. 2006)

electronegative the network-modifier cations. Both variables probably lead to shrinkage and deformation of the cavity volumes in which $\mathrm{N}_{2}$ is dissolved. This likely explains the deviations from Henry's Law behavior illustrated in Fig. 16.

When the solubility deviates from Henry's Law behavior, data from ${ }^{15} \mathrm{~N}$ magic angle spinning nuclear magnetic resonance (MAS NMR) of the melts indicate that nitrogen is dissolved as nitrosyl groups (Roskosz et al. 2006). Solution of this species in silicate glasses and melts may be expressed as (Mysen and Richet 2019; chapter 16);

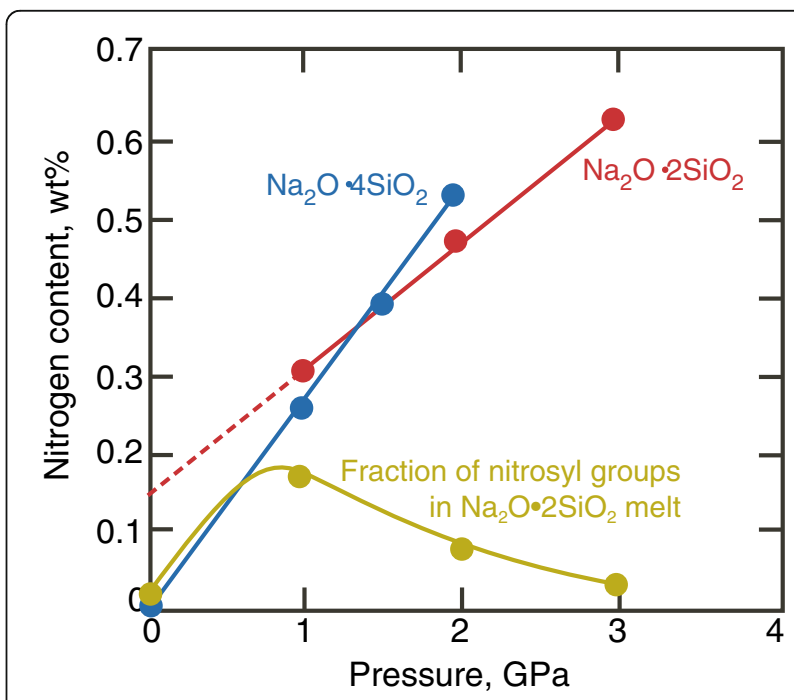

Fig. 16 Solubility of nitrogen under oxidizing conditions in $\mathrm{Na}_{2} \mathrm{O} \cdot 2 \mathrm{SiO}_{2}$ and $\mathrm{Na}_{2} \mathrm{O} \cdot 4 \mathrm{SiO}_{2}$ melt as a function of pressure. Also shown is the portion of nitrogen that formed nitrosyl groups in $\mathrm{Na}_{2} \mathrm{O} \cdot 2 \mathrm{SiO}_{2}$ melts (data from Roskosz et al. 2006) 


$$
12 \mathrm{Q}^{\mathrm{n}}(\mathrm{M})+3 \mathrm{O}_{2}+2 \mathrm{~N}_{2} \Leftrightarrow 2 \mathrm{Q}^{\mathrm{n}-1}(\mathrm{~N})+6 \mathrm{Q}^{\mathrm{n}-1}(\mathrm{M}) .
$$

where $Q^{n}(M)$ and $Q^{n-1}(M)$ represent silicate structures in which metal cations, $M$, are network-modifiers. The $\mathrm{Q}^{\mathrm{n}-1}(\mathrm{~N})$-species is a structural entity where nitrogen as $\mathrm{N}^{3+}$ is a network-modifying cation in the form of a nitrosyl group in replacement of a metal cation. In other words, formation of nitrosyl groups in a silicate melt and glass results in silicate depolymerization. This contrasts with solution of simple $\mathrm{N}_{2}$ molecules, which does not affect silicate melt polymerization. This is an example, therefore, illustrating how solution of volatiles not only depends on melt composition (and structure), but affects the silicate structure itself.

Reducing conditions The fluid/melt partition coefficient for reduced nitrogen is temperature-dependent just as it is $\mathrm{N}_{2}$ (Fig. 14). The temperature-dependence results in a $\Delta \mathrm{H}$-value of $-5.9 \pm 0.9 \mathrm{~kJ} / \mathrm{mol}$ under the assumption of no pressure-dependence in the $0.6-1.4 \mathrm{GPa}$ pressure range of those experiments (Mysen 2018a). This $\Delta \mathrm{H}$-value is significantly less than in the case of molecular $\mathrm{N}_{2}$ with its enthalpy value at $-20 \pm 4 \mathrm{~kJ} / \mathrm{mol}$ (Mysen 2018b) suggesting, perhaps, greater structural similarity between reduced nitrogen species in fluids and melts than is the case for molecular $\mathrm{N}_{2}$.

The nitrogen solubility in hydrogen-free silicate melt at or near ambient pressure, be they chemically complex natural magmatic liquids or chemically simpler silicate melts, is insensitive to oxygen fugacity at least from oxidizing conditions until redox conditions near those defined by the IW oxygen buffer $\left(2 \mathrm{Fe}+\mathrm{O}_{2} \Leftrightarrow 2 \mathrm{FeO}\right)$ are reached (near $10^{-10} \mathrm{MPa}$ at the experimental temperature of $1425^{\circ} \mathrm{C}$ of the experiments in Fig. 18; see Libourel et al. 2003; Miyazaki et al. 2004). With a further $\mathrm{f}_{\mathrm{O} 2}$ decrease, the nitrogen solubility increases rapidly (Fig. 17). These are conditions that may have existed during formation of chondrite, during proto-Earth formation, and early terrestrial evolution (Wade and Wood 2005; Cody et al. 2008).

Under conditions more reducing than that defined by the IW oxygen buffer, absent hydrogen, nitrogen likely forms nitride complexes, either with Fe or with nitrogen replacing oxygen in silicate structures to create oxynitride complexes, or both. Oxynitride formation can be expressed as a redox-driven reaction that involves changes in silicate melt polymerization;

$$
\mathrm{Q}^{\mathrm{n}}(\mathrm{M})+\mathrm{N}_{2} \Leftrightarrow \mathrm{Q}_{\mathrm{N}}^{\mathrm{n}-2}(\mathrm{M})
$$

In this expression, the $\mathrm{Q}^{\mathrm{n}-2} \mathrm{~N}(\mathrm{M})$ is an oxynitride complex. Its silicate structure is more depolymerized than $\mathrm{Q}^{\mathrm{n}}(\mathrm{M})$ (Mysen and Richet 2019; chapter 16), so this nitrogen solution mechanism is a depolymerization mechanism. That behavior contrasts with nitride formed by bonding with metal to create metal nitride

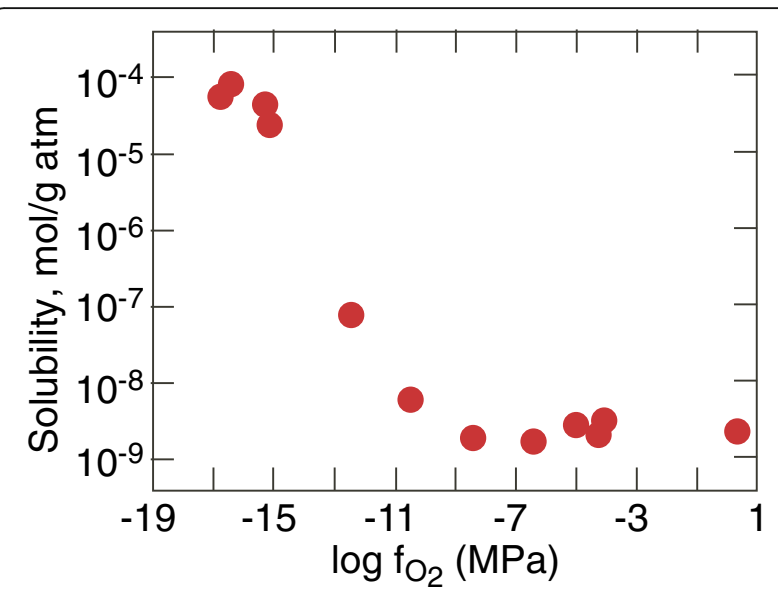

Fig. 17 Nitrogen solubility in basalt melt as a function of oxygen fugacity at ambient pressure and high temperature (data from Libourel et al. 2003)

complexes. In such a case, metal cations are extracted from their network-modifying role, thus resulting in silicate polymerization;

$$
1 / 2 \mathrm{xN}_{2}+\mathrm{yQ}^{\mathrm{n}-1} \Leftrightarrow \mathrm{M}_{\mathrm{y}} \mathrm{N}_{\mathrm{x}}+\mathrm{yQ}^{\mathrm{n}}
$$

where $Q^{n-1}$ and $Q^{n}$ are silicate species and $M_{y} N_{x}$ is a metal nitride complex.

The nitrogen solubility in hydrogen-bearing silicate melt- $\mathrm{NOH}$ and melt-COHN systems, whether under reducing and oxidizing conditions (Mysen et al. 2008; Mysen and Fogel 2010; Kadik et al. 2015) increases with increasing pressure (Fig. 18), but is greater under reducing conditions. When conditions are more reducing than those defined by the IW buffer, the nitrogen solubility does, though, continue to increase with increasing hydrogen fugacity (decreasing oxygen fugacity) (Kadik et al. 2011, 2013, 2015; see also Fig. 18) similar to that observed at ambient pressure in the absence of hydrogen (Fig. 17).

Decreasing oxygen fugacity results in a gradual decrease in the abundance ratio between molecular nitrogen, $\mathrm{N}_{2}$, and more reduced $\mathrm{N}$-bearing species, $\Sigma \mathrm{NH}_{\mathrm{n}}$ (Mysen et al. 2008; Li and Keppler 2014). There are several H-bearing reduced N-species. Their types and proportions depend on hydrogen fugacity (Fig. 19). Under reducing conditions such as those defined by the iron-wüstite buffer (IW), the N-bearing species in melts and fluids are almost exclusively ammine groups, $\mathrm{NH}_{2}{ }^{-}$ and molecular $\mathrm{NH}_{3}$ (Mysen et al. 2014), whereas under intermediate redox conditions, illustrated with the magnetite-wüstite (MW) buffer in Fig. 19, molecular $\mathrm{N}_{2}$ is more abundant and the reduced nitrogen species is in the form of an amide group, $\mathrm{NH}_{2}{ }^{+}$.

The simple equilibrium, 

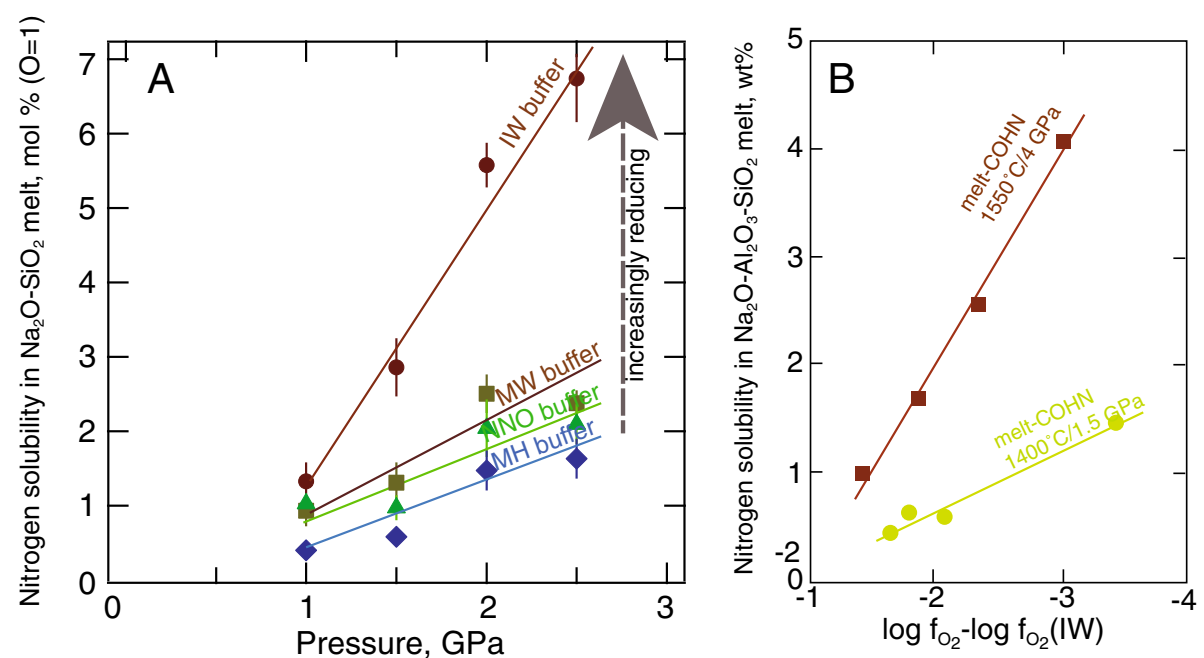

Fig. 18 Nitrogen solubility in alkali aluminosilicate melts as a function of pressure at different oxygen buffers. a At oxygen fugacity above that of the IW buffer (data from Mysen et al. 2008). b Data at oxygen fugacity below that of the IW buffer (data from Kadik et al. 2011, 2013, 2015)

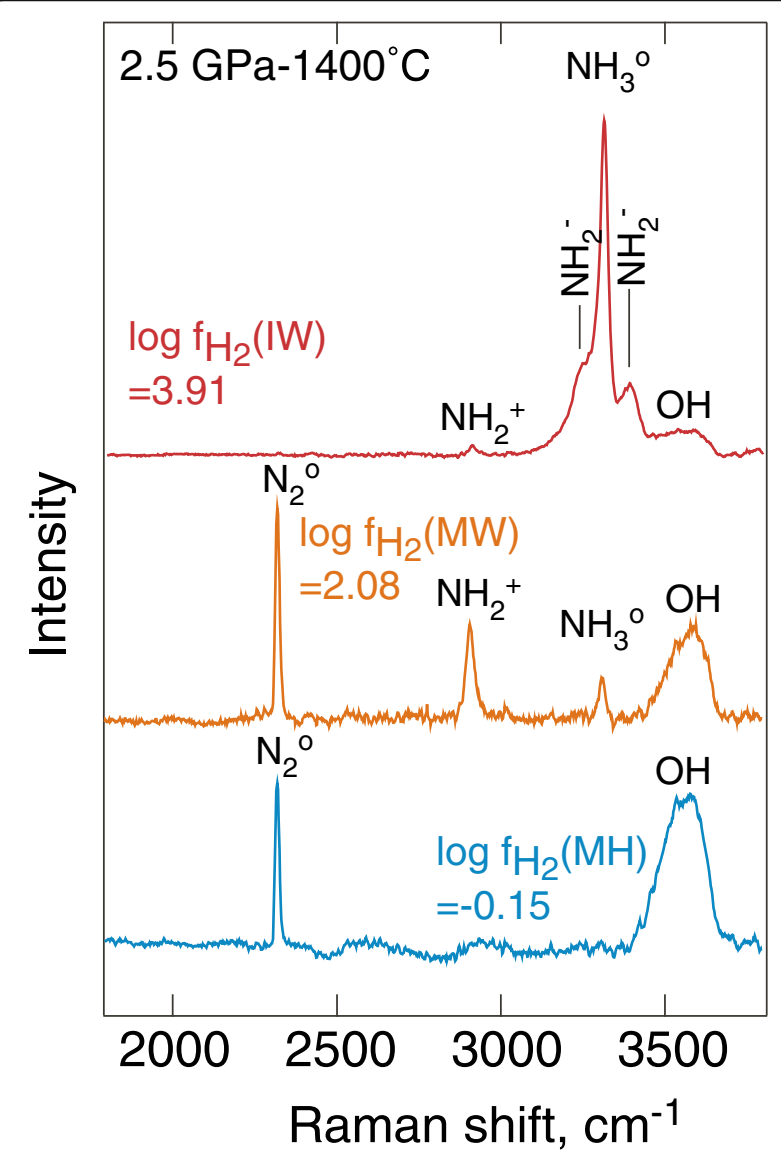

Fig. 19 Raman spectra of quenched silicate melts as a function of the hydrogen fugacity at which they equilibrated at $2.5 \mathrm{GP}$ and $1400{ }^{\circ} \mathrm{C}$ (modified after Mysen and Fogel 2010)

$$
2\left(\mathrm{SiO}_{3} \mathrm{NH}_{2}\right)^{4-}+\mathrm{H}_{2}=\mathrm{SiO}_{4}{ }^{4-}+2 \mathrm{NH}_{3},
$$

describes the relationship between coexisting molecular ammonia and ammine groups in melts and coexisting COHN fluids (Fig. 20). In this expression, the $\left(\mathrm{SiO}_{3} \mathrm{NH}_{2}\right)^{4-}$ group represents an $\mathrm{SiO}_{4}{ }^{4-}$ tetrahedron with one of the oxygens replaced by the $\mathrm{NH}_{2}{ }^{-}$group (Mysen et al. 2014). Here, the $\mathrm{NH}_{2}{ }^{-} / \mathrm{NH}_{3}$ abundance ratio decreases as a melt becomes more polymerized and as the temperature increases (Fig. 21). In other words, as a melt becomes more polymerized and, therefore, silicate-rich, the activity of oxygen increases. The

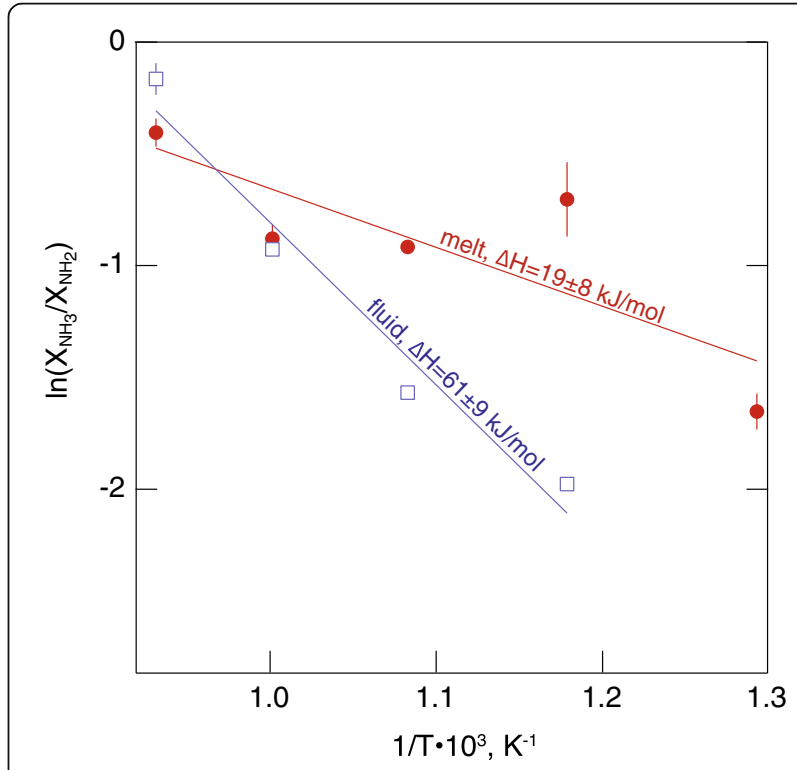

Fig. $20 \mathrm{NH}_{3} / \mathrm{NH}_{2}$ abundance ratio as a function of Temperature (1/ T, kelvin) in sodium silicate melts (data from Mysen and Fogel 2010) 


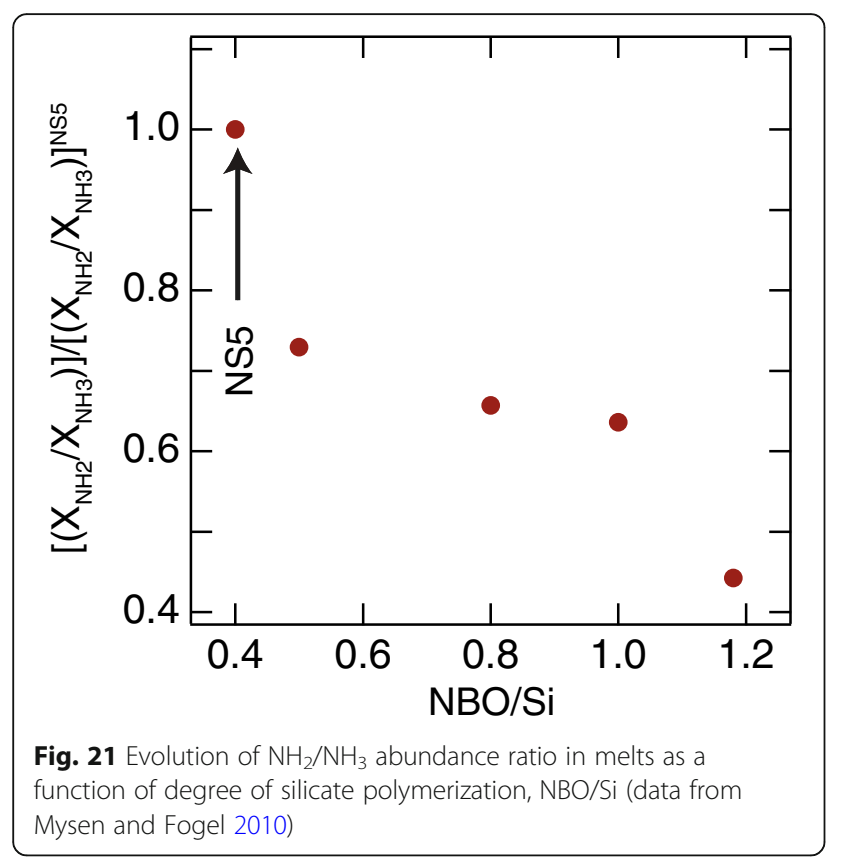

abundance of $\mathrm{NH}_{2}^{-}$groups, formed by exchange with oxygen in the silicate network, also increases. The solubility of $\mathrm{NH}^{-}{ }_{2}$ likely is greater than molecular $\mathrm{NH}_{3}$ species. Therefore, the bulk composition of magma affects nitrogen transport capacity. A similar relationship exists for coexisting fluid, but in this case, the $\mathrm{NH}_{2}{ }^{-} / \mathrm{NH}_{3}$ abundance ratio is more sensitive to temperature $(\Delta \mathrm{H}=61 \pm 9 \mathrm{~kJ} / \mathrm{mol})$ than is the case for melts $(\Delta \mathrm{H}=$ $19 \pm 8 \mathrm{~kJ} / \mathrm{mol}$ ). It is possible that this difference reflects the increasing pressure with increasing temperature during the experiments summarized in Fig. 21 (see Mysen et al. 2014). Increasing pressure increases the silicate solubility in the fluids. Given that the $\mathrm{NH}_{2}{ }^{-}$groups form bonding with $\mathrm{Si}^{4+}$ in silicate tetrahedra, it is indeed possible that this is the reason for the apparent greater $\Delta \mathrm{H}$-value from the fluid experiments.

\section{Conclusions}

The oxygen fugacity is the most important factor affecting nitrogen abundance and distribution in the Earth because nitrogen speciation depends on $\mathrm{f}_{\mathrm{O} 2}$ in the oxygen fugacity range of the Earth's interior. The different nitrogen species, in turn, exhibit significantly different solubility behavior and partitioning behavior among minerals, melts, and fluids. These features need attention when the role of nitrogen in Earth formation and evolution is under consideration.

As an example, during the earliest stages of the Earth's formation, the redox conditions likely were 1-3 orders of magnitude below that of the iron-wüstite buffer (O'Neill 1991; Righter and Drake 1999; Gessmann and Rubie 2000; Wade and Wood 2005). Under such conditions, $\mathrm{NH}_{3}, \mathrm{CH}_{4}, \mathrm{H}_{2} \mathrm{O}$, and $\mathrm{H}_{2}$ are the dominant species in the C-O-H-N system (Mysen et al. 2008; Kadik et al. 2015). Nitrogen in the form of ammine groups, $\mathrm{NH}_{2}{ }^{-}$, in equilibrium with $\mathrm{NH}_{3}$ replaces one or more of the oxygens in silicate tetrahedra. An equilibrium between the nitrogen species and the silicate structure in its simplest form in principle can be written as follows:

$$
\mathrm{Si}_{2} \mathrm{O}_{7}{ }^{6-}+\mathrm{NH}_{3} \Leftrightarrow \mathrm{SiO}_{3}(\mathrm{OH})^{3-}+\mathrm{SiO}_{3}\left(\mathrm{NH}_{2}\right)^{3-} .
$$

The oxygen fugacity conditions commonly considered for the interior of the modern Earth, which are between those of the QFM and IW oxygen buffer (Carmichael and Ghiorso 1990; Wade and Wood 2005; McCammon 2005), are several orders of magnitude more oxidizing than those existing during the Earth's early formation. It follows that the solubility mechanism of nitrogen in magmatic processes in the interior of the modern Earth probably can be described with equilibria such as (Mysen et al. 2008);

$$
\mathrm{SiO}_{4}{ }^{4-} \ldots \mathrm{NH}_{2}{ }^{+}+\mathrm{H}_{2} \Leftrightarrow \mathrm{SiO}_{4}{ }^{4-} \ldots \mathrm{H}^{+}+\mathrm{NH}_{3} .
$$

In this expression, the $\mathrm{NH}_{2}{ }^{+}$and $\mathrm{H}^{+}$are linked to nonbridging oxygen in the silicate tetrahedra and serve, therefore, as network-modifiers.

The structural role of $\mathrm{NH}_{2}^{-}$groups in Eq. (8) differs, therefore, from the behavior of $\mathrm{NH}_{2}{ }^{+}$groups in expression (9). In Eq. (8), an Si-O-Si bridge is cleaved and the oxygen formerly forming a bridge is replaced by an $\mathrm{OH}^{-}$group and an $\mathrm{NH}_{2}{ }^{-}$group. In Eq. (9), which describes moderately reducing conditions, replacement of a network-modifying cation with $\mathrm{NH}_{2}{ }^{+}$as a modifier has no effect on the overall degree of polymerization of the silicate.

Under redox conditions more oxidizing that those defined approximately by the QFM buffer, the principal nitrogen species is molecular $\mathrm{N}_{2}$. In this form, nitrogen in fluids and melts are the same:

$$
\mathrm{N}_{2} \text { (fluid) } \Leftrightarrow \mathrm{N}_{2} \text { (melt). }
$$

Expressions (8)-(10) illustrate mechanisms of nitrogen solubility and solution mechanisms in most magmatic environments in planetary interiors, be they modern or primordial. The nitrogen solubility in magma depends significantly on which of those solution mechanisms dominate.

The effect of solution mechanisms on nitrogen solubility, governed primarily by $\mathrm{f}_{\mathrm{o} 2}$, is well illustrated by the behavior of nitrogen in subduction zones in which the oxygen fugacity ranges from oxidizing to quite reducing. Subduction zones are major venues for nitrogen flux into and out of the Earth (Busigny et al. 2011) with oxygen fugacity during nitrogen release a major factor determining the fate of nitrogen ( $\mathrm{Li}$ and Keppler 2014; Mallik et al. 2018). Under oxidizing conditions such as 
those defined by the QFM buffer and above [Eq. (10)], which is common in the upper $100 \mathrm{~km}$ of subduction zones (Carmichael and Ghiorso 1990), $\mathrm{N}_{2}$ is a principal nitrogen species. Nitrogen dissolved as $\mathrm{N}_{2}$ in subduction zone magmas likely is recycled and returned to the oceans and the atmosphere because molecular $\mathrm{N}_{2}$ is incompatible in silicate melts and minerals and is released, therefore, to a fluid phase, which ascends to the surface. Under more reducing conditions such as those of the MW buffer and below [Eq. (8) and (9)], nitrogen exists in reduced form where it dissolves in minerals as described above (mica, feldspar, garnet, pyroxene and shallow depth, and wadsleyite and bridgmanite at greater depth). This nitrogen descends into the lithosphere and below likely will not be released back into the oceans and the atmosphere. The different solubility behavior of oxidized $\left(\mathrm{N}_{2}\right)$ and reduced $\left(\mathrm{NH}_{3}, \mathrm{NH}_{2}{ }^{+}, \mathrm{NH}_{2}^{-}\right)$nitrogen in mantle melts and minerals in the Earth's interior would lead to an increase in mantle nitrogen through Earth history and a decrease in nitrogen abundance in its oceans and atmosphere. Because the Earth's interior is undersaturated with respect to nitrogen (e.g., Yoshioka et al. 2018), this nitrogen is not returned to the Earth's surface even during melting or fluid release because of the compatible nature of reduced nitrogen in silicate minerals at high temperature and pressure (Busigny et al. 2011). This is why nitrogen at or near the Earth's surface cannot be used to characterize the behavior of nitrogen and its isotopes in the deep interior of the Earth.

\section{Acknowledgments}

Instrument, electronics, and library support was provided by Geophysical Laboratory technical staff. The manuscript also was reviewed by Dionysis Foustoukos and two external reviewers.

\section{Funding}

The research in this review was supported by endowment funds from the Carnegie Institution of Washington, and grants EAR-1212754 and EAR-1250449 from the National Science Foundation.

\section{Availability of data and materials}

This is a review paper. All data discussed here are in the original papers cited in the text.

\section{Authors' contributions}

All research of the manuscript was by the author. The author read and approved the final manuscript.

\section{Competing interests}

The author declares that he has no competing interests.

\section{Publisher's Note}

Springer Nature remains neutral with regard to jurisdictional claims in published maps and institutional affiliations.
Received: 29 November 2018 Accepted: 30 April 2019

Published online: 20 May 2019

\section{References}

Adler JF, Williams Q (2005) A high-pressure X-ray diffraction study of iron nitrides: implications for Earth's core. J Geophys Res 110. https://doi.org/10.1029/ 2004JB003103

Alexander MOD, Fogel M, Yabuta H, Cody GD (2007) The origin and evolution of chondrites recorded in the elemental and isotopic compositions of their macromolecular organic matter. Geochim Cosmochim Acta 71:4380-4403

Armstrong LS, Hirschmann MM, Stanley BD, Falksen EG, Jacobsen SD (2015) Speciation and solubility of reduced C-O-H-N volatiles in mafic melt: implications for volcanism, atmospheric evolution, and deep volatile cycles in the terrestrial planets. Geochim Cosmochim Acta 171:283-302

Bassett WA, Shen AH, Bucknum M, Chou IM (1994) A new diamond cell for hydrothermal studies to $2.5 \mathrm{GPa}$ and from $-190^{\circ} \mathrm{C}$ to $1200^{\circ} \mathrm{C}$. Rev Sci Instrum 64:2340-2345

Bebout GE, Fogel ML, Cartigny P (2013) Nitrogen: highly volatile yet surprisingly compatible. Elements 9:333-338

Bebout GE, Ryan JG, Leeman WP, Bebout AE (1999) Fractionation of trace elements by subduction-zone metamorphism-effect of convergent-margin thermal evolution. Earth Planet Sci Lett 171:63-81

Bergin EA, Blake GA, Ciesla F, Hirschmann MM, Li J (2015) Tracing the ingredients for a habitable earth from interstellar space through planet formation. Proc US Natl Acad Sci 112:8965-8970

Busigny V, Bebout GE (2013) Nitrogen in the silicate earth: speciation and isotopic behavior during mineral-fluid interactions. Elements 9:353-358

Busigny V, Cartigny P, Philippot P (2011) Nitrogen in ophiolitic meta-gabbros: a reevaluation of modern nitrogen fluxes in subduction zones and implication for the early earth atmosphere. Geochim Cosmochim Acta 75:7502-7221

Carmichael ISE, Ghiorso MS (1990) Controls on oxidation-reduction relations in magmas. In: Nicholls J, Russell JK (eds) Modern methods of igneous petrology: understanding magmatic processes. The Mineralogical Society of America, Washington, DC, pp 191-212

Carroll MR, Draper DS (1994) Noble gases as trace elements in magmatic processes. Chem Geol 117:37-56

Cody GD, Alexander CMOD, Yabuta H, Kilcoyne ALD, Araki T, Ade H, Dera P, Fogel ML, Militzer B, Mysen B (2008) Organic thermometry for chondritic parent bodies. Earth Planet Sci Lett 272:446-455

Dalou C, Hirschmann MM, von der Handt A, Mosenfelder J, Armstrong LS (2017) Nitrogen and carbon fractionation during core-mantle differentiation at shallow depth. Eart Planet Sci Lett 458:141-151

De Corte K, Cartigny P, Shatsky VS, Sobolev NV, Javoy M (1998) Evidence of fluid inclusions in metamorphic microdiamonds from the Kokchetav massif, northern Kazakhstan. Geochim Cosmochim Acta 62:3765-3773

Elkins LT, Fischer TP, Hilton DR, Sharp ZD, McNight S, Walker J (2006) Tracing nitrogen in volcanic and geothermal volatiles from the Nicaraguan volcanic front. Geochim Cosmochim Acta 70:5215-5235

Fogel ML, Steele A (2013) Nitrogen in extraterrestrial environments: clues to the possible presence of life. Elements 9:367-372

Gessmann CK, Rubie DC (2000) The origin of the depletions of $\mathrm{V}, \mathrm{Cr}$ and $\mathrm{Mn}$ in the mantles of the earth and moon. Earth Planet Sci Lett 184:95-187

Goldblatt C, Claire M, Lenton T, Matthews A, Watson A, Zahnle K (2009) Nitrogenenhanced greenhouse warming on early earth. Nat Geosci 2:894-896

Grewal DS, Dasgupta R, Sun C, Tsuno K, Castin C (2019) Delivery of carbon, nitrogen, and sulfur to the silicate earth by giant impact. Sci Adv 23. https:// doi.org/10.1126/sciadv.aau3669

Halama R, Bebout GE, John T, Scambelluri M (2014) Nitrogen recycling in subducted mantle rocks and implications for the global nitrogen cycle. Internat. J Earth Sci 103:2081-2099

Hall A (1999) Ammonium in granites and its petrogenetic significance. Earth Sci Rev 45:145-165

Halliday AN (2013) The origins of volatiles in terrestrial planets. Geochim Cosmochim Acta 105:146-171

Honma H, Itihara Y (1981) Distribution of ammonium minerals in metamorphic and granitic rocks. Geochim Cosmohim Acta 45:983-988

Javoy M, Pineau F (1991) The volatiles record of a "popping" rock from the midAtlantic ridge at $14 \mathrm{~N}$ : chemical and isotopic composition of gas trapped in the vesicles. Earth Planet Sci Lett 107:598-611

Johnson B, Goldblatt C (2015) The nitrogen budget of earth. Earth-Sci Rev 148:150-173 
Kadik AA, Koltashev W, Kryukova EB, Plotnichenko VG, Tsekhonya TI, Kononkova $\mathrm{NN}$ (2015) Solubility of nitrogen, carbon, and hydrogen in FeO- $\mathrm{Na}_{2} \mathrm{O}-\mathrm{Al}_{2} \mathrm{O}_{3}$ $\mathrm{SiO}_{2}$ melt and liquid Iron alloy: influence of oxygen fugacity. Geochem Int 53:849-868

Kadik AA, Kurovskaya NA, Ignat'ev YA, Kononkova NN, Koltashev W, Plotnichenko VG (2011) Influence of oxygen fugacity on the solubility of nitrogen, carbon, and hydrogen in $\mathrm{FeO}-\mathrm{Na}_{2} \mathrm{O}-\mathrm{SiO}_{2}-\mathrm{Al}_{2} \mathrm{O}_{3}$ melts in equilibrium with metallic iron at $1.5 \mathrm{GPa}$ and $1400^{\circ} \mathrm{C}$. Geochem Int 49:429-438

Kadik AA, Litvin YA, Koltashev W, Kryukova EB, Plotnichenko VG, Tsekhonya TI, Kononkova NN (2013) Solution behavior of reduced N-H-O volatiles in FeO$\mathrm{Na}_{2} \mathrm{O}-\mathrm{SiO}_{2}-\mathrm{Al}_{2} \mathrm{O}_{3}$ melt equilibrated with molten $\mathrm{Fe}$ alloy at high pressure and temperature. Phys Earth Planet Inter 214:14-24

Kaminsky FV, Wirth R (2017) Nitrides and carbonitrides from the lowermost mantle and their importance in the search for Earth's "lost" nitrogen. Am Mineral 102:1667-1676

LeLosq C, Mysen BO, Cody GD (2015) Water and magmas: insights about the water solution mechanisms in alkali silicate melts from infrared, Raman, and ${ }^{29} \mathrm{Si}$ solid-state NMR spectroscopies. Progr Earth Planet Sci 22:2. https://doi. org/10.1186/s40645-015-0052-7

Li J, Agee CB (1996) Geochemistry of mantle-core differentiation at high pressure. Nature 381:686-689

Li Y, Huang RF, Wiedenbeck M, Keppler H (2015) Nitrogen distribution between aqueous fluids and silicate melts. Earth Planet Sci Lett 411:218-228

Li Y, Keppler H (2014) Nitrogen speciation in mantle and crustal fluids. Geochim Cosmochim Acta 129:13-32

Li Y, Wiedenbeck M, Schcheka S, Keppler H (2013) Nitrogen solubility in upper mantle minerals. Earth Planet Sci Lett 377-378:311-328

Libourel G, Marty B, Humbert F (2003) Nitrogen solubility in basaltic melt. Part I. effect of oxygen fugacity. Geochim Cosmochim Acta 67(21):4123-4136

Litasov KD, Shatskiy A, Ponomarev DS, Gavryushkin PN (2017) Equations of state of iron nitrides $\varepsilon-\mathrm{Fe}_{3} \mathrm{~N}_{\mathrm{x}}$ and $\gamma-\mathrm{Fe}_{4} \mathrm{~N}_{\mathrm{y}}$ to $30 \mathrm{GPa}$ and $1200 \mathrm{~K}$ and implication for nitrogen in the Earth's core. J Geophys Res 122:3574-3584

Mallik A, Li Y, Wiedenbeck M (2018) Nitrogen within the Earth's atmospheremantle system assessed by recycling in subduction zones. Earth Planet Sci Lett 482:556-566

Marty B (2012) The origins and concentrations of water, carbon, nitrogen and noble gases on earth. Earth Planet Sci Lett 313-314:56-86

McCammon C (2005) Mantle oxidation state and oxygen fugacity: constraints on mantle chemistry, structure and dynamics. In: van der Hilst RD, Bass JD, Matas J, Trampert J (eds) Earth's deep mantle: structure, composition, and evolution. American Geophysical Union, Washington DC, pp 221-242

Mitchell EC, Fischer TP, Hilton DR, Hauri EH, Shaw AM, de Moor JM, Sharp ZD, Kazahaya K (2010) Nitrogen sources and recycling at subduction zones: insights from the Izu-Bonin-Mariana arc. Geochem Geophys Geosyst 11 https://doi.org/10.1029/2009GC002783

Miyazaki A, Hiyagon H, Sugiura N (1995) Solubility of nitrogen and argon in basalt melt under oxidizing conditions. In Farley KA (ed) Volatiles in the Earth and Solar System, pp 276-283. American Inst Physics, Washington DC

Miyazaki A, Hiyagon H, Sugiura N, Hirose K, Takahashi E (2004) Solubilities of nitrogen and noble gases in silicate melts under various oxygen fugacities: implications for the origin and degassing history of nitrogen and noble gases in the earth. Geochim Cosmochim Acta 68(2):387-401

Mysen BO (2018a) Mass transfer in the Earth's interior: fluid-melt interaction in aluminosilicate-C-O-H-N systems at high pressure and temperature under oxidizing conditions. Proc Earth Planet Sci 5:6. https://doi.org/10.1186/ s40645-017-0161-6

Mysen BO (2018b) Solution mechanisms of COHN fluids in melts to upper mantle temperature, pressure, and redox conditions. Am Mineral 103:1780-1788

Mysen BO, Fogel ML (2010) Nitrogen and hydrogen isotope compositions and solubility in silicate melts in equilibrium with reduced $(\mathrm{N}+\mathrm{H})$-bearing fluids at high pressure and temperature: effects of melt structure. Am Mineral 95(7): 987-999

Mysen BO, Richet P (2019) Silicate glasses and melts: structure and properties, vol 728, 2nd edn. Elsevier, New York

Mysen BO, Tomita T, Ohtani E, Suzuki A (2014) Speciation of and D/H partitioning between fluids and melts in silicate - D-O-H-C-N systems determined in-situ at upper mantle temperatures, pressures, and redox conditions. Am Mineral 99:578-588
Mysen BO, Yamashita S, Chertkova N (2008) Solubility and solution mechanisms of $\mathrm{NOH}$ volatiles in silicate melts at high pressure and temperature-amine groups and hydrogen fugacity. Am Mineral 93:1760-1770

Nieder R, Benbi DK (2008) Carbon and nitrogen in the terrestrial environment. p. 430. Springer, Berlin

O'Neill HSC (1991) The origin of the Moon and the early history of the Earth—a chemical model. Part 2: the Earth. Geochem Cosmochim Acta 55:1159-1172

Palya AP, Buick IS, Bebout GE (2011) Storage and mobility of nitrogen in the continental crust: evidence from partially melted metasedimentary rocks, Mt. Stafford, Australia. Chem Geol 281:211-226

Plessen B, Harlov DE, Henry D, Guidotti CV (2010) Ammonium loss and nitrogen isotopic fractionation in biotite as a function of metamorphic grade in metapelites from western Maine, USA. Geochim Cosmochim Acta 74:4759-4771

Polyanov YN, Bataleva YV, Sokol AG, Borzdov YM, Kupriyanov IN, Reutsky VN, Sobolev NV (2014) Mantle-slab interaction and redox mechanism of diamond formation. Proc Natl Acad Sci U S A 51:20408-20413

Righter K, Drake MJ (1999) Effect of water on metal-silicate partitioning of siderophile elements: a high pressure and temperature terrestrial magma ocean and core formation. Earth Planet Sci Lett 171:383-399

Roskosz M, Bouhifd MA, Jephcoat AP, Marty B, Mysen BO (2013) Nitrogen solubility in molten metal and silicate at high pressure and temperature. Geochim Cosmochim Acta 121:15-28

Roskosz M, Mysen BO, Cody GD (2006) Dual speciation of nitrogen in silicate melts at high pressure and temperature: an experimental study. Geochim Cosmochim Acta 70:2902-2918

Rubie DC, Frost DJ, Mann U, Asahara Y, Tsuno K, Nimmo F, Kegler P, Holzheid A, Palme H (2011) Heteroegeneous accretion, composition and core-mantle differentiation of the Earth. Earth Planet Sci Lett 301:31-42

Sano Y, Takahata N, Nishio Y, Fischer TP, Williams SN (2001) Volcanic flux of nitrogen from the Earth. Chem Geol 171:263-271

Smith EM, Kopylova MG (2014) Implications of metallic iron for diamonds and nitrogen in the sublithospheric mantle. Can J Earth Sci 51:510-516

Wade J, Wood BJ (2005) Core formation and the oxidation state of the Earth. Earth Planet Sci Lett 236:78-95

Watenphul A, Wunder B, Heinrich W (2009) High-pressure ammonium-bearing silicates: implications for nitrogen and hydrogen storage in the Earth's mantle. Amer Mineral 94:283-292

Watenphul A, Wunder B, Wirth R, Heinrich W (2010) Ammonium-bearing clinopyroxene: a potential nitrogen reservoir in the Earth's mantle. Chem Geol 270:240-248

Yoshioka T, Wiedenbeck M, Shcheka S, Keppler H (2018) Nitrogen solubility in deep mantle and the origin of the Earth's primordial nitrogen budget. Earth Planet Sci Lett 488:134-143

Zhang C, Duan Z, Li M (2010) Interstitial voids in silica melts and implication for argon solubility under high pressures. Geochim Cosmochim Acta 74:4140-4149

Zhang Y, Yin QZ (2012) Carbon and other light element contents in the Earth's core based on first-principles molecular dynamics. Proc Natl Acad Sci U S A 109:19579-19583

\section{Submit your manuscript to a SpringerOpen ${ }^{\circ}$ journal and benefit from:}

- Convenient online submission

- Rigorous peer review

- Open access: articles freely available online

- High visibility within the field

- Retaining the copyright to your article

Submit your next manuscript at $>$ springeropen.com 